\title{
As Formas Africanas de Auto-Inscrição
}

Achille Mbembe

O objetivo do texto é analisar e criticar as diferentes formas com as quais se tentou construir e representar a identidade africana a partir, basicamente, de um discurso nativista, por um lado, e outro instrumentalista, da África e de seu povo. Baseado em uma interpretação crítica dos diversos essencialismos construídos em torno de uma suposta leitura pan-africana e consensual do mundo, o autor alerta para os perigos advindos da busca irrefletida de uma alteridade africana sem o devido reconhecimento das especificidades culturais, políticas e geográficas em África. Tanto o economicismo quanto a metafísica da diferença são historicismos vistos pelo autor como formas fadadas ao fracasso, tendo em vista a pluralidade de signos e contextos com as quais se tentou construir a autodeterminação e a auto-afirmação africanas ao longo do século XX.

Palavras-chave: auto-inscrição; auto-afirmação; self; autonomia; imaginário coletivo africano; políticas da africanidade.

\footnotetext{
* Ato Quayso e Ruth Marshall criticaram uma versão anterior deste artigo. Sarah Nutal, Françoise Vergès, Carol Gluck e Candace Vogler forneceram comentários adicionais. Recebi um contínuo estímulo de Bogumil Jewsiewicki, Pierre Nora, Carol Breckenridge, Arjun Appadurai e Dilip Gaonkar. Trechos deste texto foram apresentados em conferências na Cidade do Cabo, em agosto de 2000; em Patna (Índia) em fevereiro de 2001; e em Chicago, em março de 2001. Tradução de Patrícia Farias.
}

Estudos Afro-Asiáticos, Ano 23, no 1, 2001, pp. 171-209 
Achille Mbembe

\begin{abstract}
African Modes of Self-Inscription

The objective of this paper is to analyze and criticize the different endeavors to build and display African identity, basically starting with a chauvinist discussion on one hand, and an instrumental one on the other, on Africa and its people. Based on a critical interpretation of the various essential points made regarding a supposed consensual world Pan-African survey, the author warns against the perils originating from a thoughtless search of an African alterity without duly acknowledging African cultural, political and geographical specifics. Both the economicism and the metaphysics of the difference are historicisms seen by the author as doomed to fail, considering the plurality of signs and contexts on which African self-registration and self-affirmation were based throughout the $20^{\text {th }}$ century.
\end{abstract}

Keywords: self-registration; self-affirmation; self; autonomy; imaginary; African collective imaginary; African politics.

\title{
Résumé
}

\section{Les Formes Africaines d'Auto-Inscription}

Dans ce texte on cherche à examiner et remettre en cause les différents moyens employés dans la construction et la représentation de l'identité africaine, à partir d'un discours à la fois nativiste et instrumentaliste sur l'Afrique et son peuple, surtout. En prenant appui sur une interprétation critique des différents essentialismes bâtis autour d'une présumée lecture pan-africaine et consensuelle du monde, l'auteur signale les dangers d'une recherche irréfléchie de l'altérité africaine qui ne tiendrait pas compte des spécificités culturelles, politiques et géographiques de ce continent. L'économisme ainsi que la métaphysique de la différence sont des historicismes que l'auteur envisage comme des chemins voués à l'échec, face à la pluralité de signes et de contextes dont on s'est servi pour construire l'auto-détermination et l'auto-affirmation africaines au cours du XX siècle.

Mots-clé: auto-inscription; auto-affirmation; self; autonomie; imaginaire collectif africain; politiques de l'africanité.

Estudos Afro-Asiáticos, Ano 23, no 1, 2001, pp. 172-209 
$\mathrm{D}$ urante os últimos três séculos, temos visto surgir tendências intelectuais cujo objetivo tem sido conferir autoridade simbólica a certos elementos integrados ao imaginário coletivo africano. Algumas destas tendências se desenvolveram, outras permaneceram como meros esboços. ${ }^{1}$ Muito poucas são notáveis por sua riqueza e criatividade, e em menor número ainda, são aquelas tendências dotadas de uma força excepcional. Não há nada que se compare, por exemplo, à filosofia alemã, que, de Lutero a Heidegger, tem se baseado não só no misticismo religioso, mas, mais fundamentalmente, no desejo de transgredir a fronteira entre o humano e o divino.

Tampouco há algo comparável ao messianismo judaico, que, combinando desejo e sonho, enfrentou, sem nenhuma mediação, o problema do absoluto e suas promessas, desenvolvendo este último até suas mais extremas conseqüências de tragédia e desespero, enquanto ao mesmo tempo tratava a singularidade do sofrimento judeu como sendo algo sagrado, correndo o risco de torná-lo um tabu (cf. Scholem, 2000; Baer, 2000; Arendt, 1987; Goldberg, 2000). Seguindo o exemplo destas duas metanarrativas, as formas africanas de escrever o próprio selfsão inseparavelmente conectadas à problemática da autoconstrução e da moderna filosofia do sujeito. Entretanto, as similaridades acabam aí. ${ }^{2}$

Vários fatores evitaram o desenvolvimento de concepções que poderiam ter explicado o significado do passado e do presente africanos através da referência ao futuro. $\mathrm{O}$ esforço de determinar as condições sob as quais o sujeito africano podia adquirir integralmente sua própria subjetividade, tornar-se consciente de si mesmo, sem ter que prestar contas a ninguém, cedo encontrou duas formas de historicismo que o liquidaram: primeiro, o "economicismo", com sua bagagem de instrumentalismo e oportunismo político; segundo, o fardo da metafísica da diferença. ${ }^{3}$ A primeira

Estudos Afro-Asiáticos, Ano 23, no 1, 2001, pp. 173-209 
corrente de pensamento - que gosta de se apresentar como "democrática, 'radical' e progressista" - utiliza categorias marxistas e nacionalistas para desenvolver um imaginário da cultura e da política, no qual a manipulação da retórica da autonomia, da resistência e da emancipação serve como o único critério para determinar a legitimidade do discurso "africano" autêntico. A segunda corrente se desenvolveu a partir da ênfase na "condição nativa". Ela promove a idéia de uma única identidade africana, cuja base é o pertencimento à raça negra.

No centro dessas duas correntes de pensamento repousam três eventos históricos: a escravidão, o colonialismo e o apartheid. A estes eventos, um específico conjunto de significados canônicos foi atribuído. Primeiro, a idéia de que, através dos processos de escravidão, colonização e apartheid, o eu africano se torna alienado de si mesmo (divisão do self). Supõe-se que esta separação resulta em uma perda de familiaridade consigo mesmo, a ponto de o sujeito, tendo se tornado um estranho para si mesmo, ser relegado a uma forma inanimada de identidade (objetificação). Não apenas o eu não é mais reconhecido pelo Outro, como também não mais se reconhece a si próprio. ${ }^{4}$

O segundo significado canônico tem a ver com a propriedade. De acordo com a narrativa dominante, os três eventos citados acarretaram a ausência de bens, sendo assim um processo no qual os procedimentos econômicos e jurídicos levaram à expropriação material. A isto se seguiu uma experiência singular de sujeição, caracterizada pela falsificação da história da África pelo Outro, o que resultou em um estado de exterioridade máxima (estranhamento) e de "desrazão". Estes dois aspectos (a expropriação material e a violência da falsificação) são considerados os principais fatores que constituem a singularidade da história africana, e da tragédia na qual ela se baseia.

Finalmente, a idéia da degradação histórica. A escravidão, a colonização e o apartheid são considerados não só como tendo aprisionado o sujeito africano na humilhação, no desenraizamento e no sofrimento indizível, mas também em uma zona de não-ser e de morte social caracterizada pela negação da dignidade, pelo profundo dano psíquico e pelos tormentos do exílio. Em todos os três casos, supõe-se que os elementos fundamentais da escravidão, da colonização e do apartheid são fatores que servem para unificar o desejo africano de se conhecer a si mesmo, de reconquistar seu destino (soberania) e de pertencer a si mesmo no mundo (autonomia).

Estudos Afro-Asiáticos, Ano 23, no 1, 2001, pp. 174-209 
Seguindo o modelo da reflexão judaica sobre o fenômeno do sofrimento, da contingência e da finitude, estes três significados poderiam ter sido utilizados como ponto de partida para uma interpretação filosófica e crítica sobre o aparentemente longo vôo em direção ao nada que a África tem experimentado durante toda a sua história. A teologia, a literatura, o cinema, a música, a filosofia política e a psicanálise também poderiam ter sido envolvidos neste processo, mas isto não ocorreu. $\mathrm{Na}$ verdade, a produção dos significados dominantes destes eventos foi colonizada por duas correntes ideológicas de pensamento: uma, nativista, outra, instrumentalista, que afirmam falar "em nome" da África como um todo. Nos trechos seguintes, examinarei estas duas correntes de pensamento e delinearei seus pontos fracos. Ao longo desta discussão, proporei formas alternativas ao aniquilamento ao qual elas levaram a reflexão sobre a experiência africana do self e do mundo. Mostrarei como as imaginaçôes africanas atuais sobre o selfnascem a partir de diversas, mas freqüentemente interconectadas, práticas, cujo objetivo é não apenas estabelecer debates factuais e morais sobre o mundo, mas abrir o caminho para a construção de um estilo próprio.

\section{Fantasias Primais}

A primeira corrente de pensamento (marxista e nacionalista) está permeada pela tensão entre o voluntarismo e a vitimização. Ela tem quatro características principais. Primeiro, uma falta de reflexividade e uma concepção instrumental do conhecimento e da ciência, no sentido de que nenhuma delas é reconhecida como autônoma. Elas são úteis, na medida em que estiverem a serviço da luta partidária. 'Esta luta é, ela própria, investida de um significado moral, já que se afirma que opõe as forças revolucionárias às conservadoras. ${ }^{10}$ A segunda característica é uma visão mecânica e reificada da história. A causalidade é atribuída a entidades fictícias e totalmente invisíveis, no entanto consideradas sempre determinantes, em última instância, da vida e do trabalho do sujeito. De acordo com esse ponto de vista, a história da África pode ser reduzida a uma série de fenômenos de sujeição interconectada em uma continuidade compacta. Considera-se que a experiência africana do mundo é determinada, a priori, por um conjunto de forças sempre as mesmas, embora aparecendo de diferentes formas - cuja

Estudos Afro-Asiáticos, Ano 23, no 1, 2001, pp. 175-209 
função é evitar o florescimento da singularidade africana, daquela parte do eu histórico africano que é irredutível a qualquer outro.

Como resultado, afirma-se que a África não é responsável pelas catástrofes que sobre ela se abatem. Supóe-se que o atual destino do Continente não advém de escolhas livres e autônomas, mas do legado de uma história imposta aos africanos, marcada a ferro e fogo em sua carne através do estupro, da brutalidade e de todo tipo de condicionantes econômicas. ${ }^{1}$ Considera-se que a dificuldade de o sujeito africano representar a si mesmo(a) como o sujeito de uma vontade livre, resulta desta longa história de subjugação. Isto leva a uma atitude ingênua e acrítica diante das chamadas lutas pela libertação nacional e dos movimentos sociais; à ênfase na violência como o melhor caminho para a autodeterminação; à fetichização do poder estatal; à desqualificação do modelo liberal de democracia; e ao sonho autoritário e populista de uma sociedade de massas. ${ }^{12}$

A terceira característica é um desejo de destruir a tradição e a crença de que a verdadeira identidade é conferida pela divisão de trabalho que faz surgir as classes sociais, em que o proletariado (rural ou urbano) tem o papel de classe universal por excelência. ${ }^{13} \mathrm{~A}$ suposição de que a classe operária é o único agenciamento prático que pode se engajar em uma atividade emancipatória, resulta na negação das múltiplas bases do poder social. ${ }^{14}$ Finalmente, este corpo de pensamentos repousa em uma relação essencialmente polêmica com o mundo. Esta polêmica relação baseia-se em um conjunto de rituais retóricos: o primeiro ritual contradiz e refuta as definiçōes ocidentais da África e dos africanos, apontando para as falsidades e preconceitos que elas têm como pressupostos; o segundo, denuncia o que o Ocidente fez (e continua fazendo) à África em nome destas definições; o terceiro, fornece as chamadas provas que, ao desqualificarem as representaçóes ficcionais do Ocidente sobre a África, e ao refutarem a afirmação de que este detém o monopólio da expressão do humano em geral, supostamente abrem um espaço em que os africanos podem finalmente narrar suas próprias fábulas em uma linguagem e voz que não podem ser imitadas, porque são verdadeiramente suas. ${ }^{15}$

O que poderia parecer a apoteose do voluntarismo, paradoxalmente é acompanhado de uma falta de profundidade filosófica e de um culto à vitimização. Filosoficamente, a temática hegeliana da identidade e da diferença, tal como classicamente exemplificada pela relação senhor/escravo, é sub-repticiamente reapropriada pelos ex-colonizados. Em uma tocante lembrança da "operação et-

Estudos Afro-Asiáticos, Ano 23, no 1, 2001, pp. 176-209 
nográfica”, os ex-colonizados atribuem uma série de características pseudo-históricas a uma entidade geográfica que está, ela mesma, subsumida a um nome racial. Estas características e este nome são, então, utilizados para identificar ou tornar possível o reconhecimento daqueles que, por possuírem tais características ou ostentarem tal nome, são considerados como pertencentes à coletividade racial e à entidade geográfica, assim definidas. À guisa de "falar com a própria voz", a figura do "nativo" é reiterada. Fronteiras entre o "nativo" e o Outro, "não-nativo", são demarcadas. Com base nestas fronteiras, pode-se, assim, distinguir entre o "autêntico" e o "não-autêntico".

No trecho que se segue, argumento que (1) as narrativas marxistas e nacionalistas sobre o eu e o mundo têm sido superficiais; (2) como conseqüência desta superficialidade, suas noçôes de autogoverno e de autonomia têm pouca base filosófica; e (3) seu privilegiamento da vitimização, em detrimento do sujeito, em última instância resulta de uma compreensão da história como feitiçaria.

Auto-afirmação, autonomia e emancipação africanas - em nome das quais o direito ao próprio eu é afirmado - não são questões novas. Quando o tráfico de escravos no Atlântico chegou ao fim, dúvidas quanto à habilidade africana para se autogovernar, ou seja, de acordo com Hegel, para controlar sua ânsia predatória e sua crueldade, ganharam mais vigor. Tais dúvidas se conectavam a outra, mais fundamental, que estava implícita na forma como a modernidade resolveu o complexo problema geral da alteridade e, dentro dele, o status do signo africano. Tanto os movimentos filantrópicos, como a intelligentsia da época, responderam a esta dúvida a partir do paradigma do Iluminismo. ${ }^{16}$

Para que se possa entender as implicações políticas destes debates, talvez eu deva assinalar que, para o pensamento iluminista, a humanidade se define pela posse de uma identidade genérica que é universal em sua essência, e da qual derivam direitos e valores que podem ser partilhados por todos. Uma natureza comum une todos os seres humanos. Ela é idêntica em cada um deles, porque a razão está em seu centro. $\mathrm{O}$ exercício da razão leva não apenas à liberdade e à autonomia, mas também à habilidade de guiar a vida individual de acordo com princípios morais e com a idéia do bem. Fora deste círculo, não há lugar para uma política do universal. Durante a fase pós-abolição, a questão era se os africanos estavam fora ou dentro do círculo, ou seja, se eles eram seres humanos como todos os outros. Em outras palavras, seria possível encontrar, entre os africa-

Estudos Afro-Asiáticos, Ano 23, no 1, 2001, pp. 177-209 
nos, o mesmo ser humano, apenas disfarçado sob diferentes formas e designações? Poderíamos considerar os corpos, as línguas, o trabalho e a vida africanos como produtos de uma atividade humana, como manifestações de uma subjetividade - ou seja, de uma consciência tal como a nossa - de forma a permitir que os consideremos, a cada um deles individualmente, como um alter ego (um outro eu)?

A estas questões, o Iluminismo ofereceu três diferentes respostas com implicações políticas relativamente distintas. Um conjunto inicial de respostas sugere que os africanos poderiam ser mantidos dentro dos limites de sua suposta diferença ontológica. $\mathrm{O}$ lado mais sombrio do Iluminismo via no signo africano algo único, e até mesmo indestrutível, que o separava de todos os outros signos humanos. A melhor testemunha desta especificidade era o corpo negro, que supostamente não continha nenhuma forma de consciência, nem tinha nenhuma das características da razão ou da beleza. ${ }^{17}$ Conseqüentemente, ele não poderia ser considerado um corpo composto de carne como o meu, porque pertenceria unicamente à ordem da extensão material e do objeto condenado à morte e à destruição. A centralidade do corpo no cálculo da sujeiçãao política explica a importância dada, ao longo do século XIX, pelas teorias da regeneração física, moral e política dos negros e, mais tarde, dos judeus.

De acordo com este lado mais sombrio do Iluminismo, os africanos teriam desenvolvido concepçōes particulares sobre a sociedade, o mundo e o bem que eles não compartilhariam com outros povos. E ocorre que tais concepçōes de forma alguma manifestariam o poder da invenção e da universalidade peculiar à razão. Tampouco as representações, a vida, o trabalho, a língua, ou os atos referentes à morte realizados pelos africanos, obedecem a qualquer regra ou lei cujo significado eles possam, por sua própria conta, conceber ou justificar. Por causa desta diferença radical, seria legítimo excluí-los, tanto de facto como de jure, da esfera da total e completa cidadania humana: eles nada têm que possa contribuir para o desenvolvimento do universal. ${ }^{18}$

Uma mudança significativa ocorreu no início da colonização. O princípio da diferença ontológica persistiu, e a preocupação com a autodeterminação foi conectada à necessidade de se "tornar civilizado". Um leve deslizamento ocorreu dentro da velha economia da alteridade. A tese da não-similaridade não foi repudiada, mas não mais se baseava somente na vacuidade do signo como tal. Ao signo foi dado um nome: a tradição. Se os africanos

Estudos Afro-Asiáticos, Ano 23, no 1, 2001, pp. 178-209 
eram tipos diferentes de seres, era porque eles tinham sua própria identidade. Esta identidade não podia ser abolida. Pelo contrário, a diferença teria de ser inscrita em uma ordem institucional distinta, enquanto, ao mesmo tempo, esta ordem seria forçada a operar a partir de uma perspectiva fundamentalmente desigual e hierarquizada. Em outras palavras, a diferença era reconhecida, mas apenas na medida em que implicasse desigualdades, que eram, além disso, consideradas naturais, no sentido de que ela justificava a discriminação e, nos casos mais extremos, a segregação. ${ }^{19}$

Mais tarde, o Estado colonial usou a tradição - ou seja, o princípio da diferença e da não-similaridade - como uma forma de governo em si mesma. Específicas formas de conhecimento foram produzidas com este objetivo. Seu propósito era canonizar a diferença e eliminar a pluralidade e a ambivalência da tradição. ${ }^{20} \mathrm{O}$ paradoxo deste processo de reificação era que, de um lado, ele parecia ser o reconhecimento desta tradição, enquanto de outro ele constituía um julgamento moral, porque, em última análise, tal tradição se tornara específica apenas para melhor indicar a extensão na qual o mundo do nativo, em sua naturalidade, não coincidia, de forma alguma, com o nosso; em suma, ele não era parte de nosso mundo, e, portanto, não podia servir como base para uma experiência de convivência em uma sociedade civil.

A terceira variante tem a ver com a política da assimilação. Aqui, vale a pena uma comparação com a experiência judaica. Tal como para a figura "dos negros", a invocação da figura dos judeus como o arquetípico outro do Ocidente foi central para a noção iluminista de Bildung (o processo formativo pelo qual o indivíduo se move em direção à autonomia). Os judeus eram percebidos como a negação da promessa iluminista de uma emancipação através do uso da razão. Em princípio, o conceito de assimilação fundou-se na possibilidade de uma experiência do mundo comum a todos os seres humanos, ou melhor, uma experiência de humanidade universal baseada na similaridade essencial entre os seres humanos.

Este mundo comum a todos os seres humanos, esta similaridade, supostamente não estavam dados, a priori, a todos. O nativo em especial deveria ser convertido a eles. Esta conversão era a condição para que ele fosse percebido e reconhecido como nosso companheiro e, por conta de sua humanidade, deixasse de ser irrepresentável e indefinível. Dadas estas condições, a assimilação consistia no reconhecimento de uma individualidade africana diferente em relação ao grupo. Os sujeitos africanos podiam ter direitos e usufruir deles, não por causa de seu pertencimento às regras da tra-

Estudos Afro-Asiáticos, Ano 23, no 1, 2001, pp. 179-209 
dição, mas pelo seu status como indivíduos capazes de pensarem por si mesmos e exercerem sua razão, esta faculdade peculiar aos humanos. ${ }^{21}$

Reconhecer esta individualidade, ou seja, esta habilidade em imaginar metas diferentes daquelas impostas pelos costumes, era se afastar da diferença. Esta deveria ser apagada e anulada se os africanos quisessem tornar-se iguais a nós tornar-se iguais a nós e quisessem, assim, ser considerados como alter ego. Desta forma, a essência da política da assimilação consistia em des-substancializar e estetizar a diferença, ao menos para uma categoria de nativos (les évolués) cooptados para o espaço da modernidade por terem sido "convertidos" e "cultivados", ou seja, tornados passíveis de se encaixarem na idéia de cidadania e do gozo dos direitos civis. Isso envolvia a passagem da tradição para a sociedade civil - mas, por meio da experiência do cristianismo e do Estado colonial. ${ }^{22}$

Quando, no período pós-escravocrata, a crítica africana levantou a questão da autogestão, herdou estes três momentos, mas não os submeteu a uma crítica coerente. Pelo contrário, sob o emblema da emancipação e da autonomia, ela aceitou, em sua maioria, as categorias básicas que o discurso ocidental usava, então, para seu relato da história universal. ${ }^{23}$ A noção de "civilização" foi uma destas categorias. Ela autorizou a distinção entre o humano e o não-humano ou o ainda-não-suficientemente-humano que poderia se tornar humano se lhe fosse dado um treinamento adequado. ${ }^{24}$ Os três vetores deste processo de domesticação eram a conversão ao cristianismo, a introdução à economia de mercado e a adoção de formas de governo racionais e iluministas (cf. Blyden, 1967). Na realidade, era menos uma questão de compreender o que levara à situação de servidão, e o que a servidão significava, do que de postular, em abstrato, a necessidade de se libertar dela.

Para os primeiros pensadores africanos modernos, a libertação da situação de servidão era equivalente, acima de tudo, à conquista do poder formal. A questão filosófica e moral fundamental - ou seja, como renegociar um laço social corrompido por relaçóes comerciais (a venda de seres humanos), pela violência das guerras sem fim e pelas catastróficas conseqüências do modo pelo qual o poder era exercido - era considerada secundária. A crítica africana não assumiu como sua tarefa primordial uma reflexão política e filosófica sobre o caráter das disputas internas que acarretaram o tráfico de escravos. Menos ainda se preocupou com as modalidades de reinvenção da convivência em uma situação na qual, com relação à filosofia da razão que ela afirmava partilhar, todas as eviden-

Estudos Afro-Asiáticos, Ano 23, no 1, 2001, pp. 180-209 
tes aparências de uma vida humana possível pareciam inexistir, e o que parecia ser política tinha mais a ver com o poder de destruir e de lucrar, do que com qualquer tipo de filosofia de vida ou razão.

Para ser exato, os nacionalismos africanos do pós-guerra, acompanhando, a este respeito, as tendências de seu tempo, substituíram o conceito de "civilizaçãa”" pelo de "progresso". Mas, eles assim o fizeram apenas para reforçar as teleologias da época. ${ }^{25} \mathrm{Ten}$ do posto de lado a possibilidade de uma reflexão propriamente filosófica sobre a condição africana, apenas a questão crua do poder permaneceu: quem podia capturá-lo e usufruí-lo foi legitimado. Para justificar o direito à soberania e à autodeterminação, e para lutar pelo poder, duas categorias foram mobilizadas: de um lado, a figura do africano como um sujeito vitimizado e espoliado; de outro, a afirmação da singularidade cultural africana (cf. Azikiwe, 1969; Nkrumah, 1961; Cabral, 1970). Ambas implicaram um profundo investimento na idéia de raça e uma radicalização da diferença.

No centro do paradigma pós-colonial da vitimização, encontramos uma leitura do eu e do mundo como sendo formados a partir de uma série de conspirações. Na história africana, supõe-se, não existe nem ironia, nem acaso. A história africana, afirma-se, é essencialmente governada por forças que estão acima do controle dos africanos. A diversidade e a desordem do mundo, assim como o caráter, em aberto, das possibilidades históricas, foram reduzidos a um ciclo espasmódico e imutável, que infinitamente se repete de acordo com uma conspiração sempre fomentada por forças que estão acima do alcance dos africanos. A própria existência é expressa, quase sempre, como vacilante. Em última análise, considerava-se o africano como apenas um sujeito castrado, o passivo instrumento de gozo do outro. Sob tais condições, não poderia haver uma visão mais radicalmente utópica que a sugestão de uma África desconectada do mundo: o sonho louco de um mundo sem $\mathrm{Ou}$ tros.

Este ódio do mundo (que também mascara um profundo desejo de reconhecimento) e esta leitura conspiratória da história eram apresentados como o discurso "democrático", "radical" e "progressista" da emancipação e da autonomia, como a base da chamada política da africanidade. ${ }^{26}$ Mas, por trás da neurose da vitimização, uma forma de pensar circular, negativa, xenófoba e racista se desenvolve. Para funcionar, ela precisa de superstições. Tem que criar ficções que depois passem como verdades. Tem que fabricar máscaras constantemente remodeladas para se adequarem

Estudos Afro-Asiáticos, Ano 23, no 1, 2001, pp. 181-209 
às necessidades de cada período. O curso da história africana é considerado como sendo determinado pela ação combinada de uma diabólica dupla formada por um inimigo - ou torturador - e uma vítima. Neste universo fechado, no qual "fazer história" consiste em aniquilar os inimigos, a política é concebida como um processo sacrificial, e a história, no fim das contas, como parte da grande economia da feitiçaria. ${ }^{27}$

\section{A Prosa do Nativismo}

Paralela a esta corrente de pensamento - que busca fundar uma política da africanidade usando as categorias da economia política marxista, ao mesmo tempo em que vê a política como um processo sacrificial e a história como feitiçaria -, uma configuração retórica desenvolveu uma temática central: a da identidade cultural. Esta corrente de pensamento caracterizou-se por uma tensão estrutural, opondo uma tendência universalizante que afirmava o pertencimento à condição humana (igualdade) à outra, particularista, que enfatizava a diferença e a especificidade, frisando não a originalidade, mas o princípio da repetição (a tradição) e os valores autóctones. O ponto em que estas duas tendências políticas e culturais convergiam era a raça. Deixe-me fazer um breve resumo da história de sua problematização no pensamento africano.

Em primeiro plano, existe a noção de "raça" e seu status nas questôes referentes ao reconhecimento dos atributos humanos. $\mathrm{Na}$ verdade, a maioria das teorias do século XIX estabelecia uma íntima relação entre o sujeito humano e o sujeito racial. A raça, em si, era entendida como um conjunto de propriedades fisiológicas visíveis e de características morais discerníveis. Considerava-se que estas propriedades e características distinguiam as espécies humanas umas das outras (cf. Kant, 1978). Mais ainda, tais propriedades fisiológicas e características morais tornavam possível classificar estas espécies dentro de uma hierarquia cujos violentos efeitos são de caráter tanto político, como econômico e cultural (ver Guiral e Temime, 1977). Como já foi dito, a classificação dominante durante o período do comércio escravista no Atlântico logo depois excluía os africanos do círculo da humanidade, ou, de qualquer forma, lhes designava um status inferior na hierarquia das raças.

Esta negação de humanidade (ou este status de inferioridade) forçou seu discurso a se expressar em uma tautologia: "somos

Estudos Afro-Asiáticos, Ano 23, no 1, 2001, pp. 182-209 
seres humanos como quaisquer outros" ${ }^{28} \mathrm{Ou}$ : "temos um passado glorioso que testemunha nossa humanidade". ${ }^{29}$ Por isso, o discurso sobre a identidade africana ficou preso em um dilema do qual luta para se libertar: será que a identidade africana participa de uma genérica identidade humana? ${ }^{30} \mathrm{Ou}$ se deve insistir, em nome da diferença e da singularidade, na possibilidade de formas culturais diversas dentro de uma mesma humanidade - formas estas cujo objetivo não é ser auto-suficiente, e cuja significação última é universal? ? $^{31}$

A apologética densidade da afirmação "somos seres humanos como quaisquer outros" apenas pode ser compreendida face à violência da negação que a precede, e que a torna não apenas possível, mas também necessária. ${ }^{32}$ A reafirmação de uma identidade humana que foi negada pelo Outro pertence, neste caso, ao discurso da reabilitação e funciona como uma forma de autovalidação (cf. Irele, 1991:79). Mas, se o discurso de reabilitação tenta confirmar que os africanos também pertencem à humanidade em geral, ele não ameaça a ficção da raça. ${ }^{33}$ A defesa da humanidade dos africanos é quase sempre acompanhada pela afirmação de que sua raça, tradições e costumes têm um caráter específico.

Nas narrativas africanas dominantes sobre o self, é a raça que torna possível fundamentar não apenas a diferença em geral, mas também a própria idéia de nação, já que se consideram os determinantes raciais como a base moral para a solidariedade política. $\mathrm{Na}$ história do ser africano, a raça é o sujeito moral e ao mesmo tempo um fato imanente da consciência. Os alicerces fundamentais da antropologia novecentista, ou seja, o preconceito evolucionista e a crença na idéia de progresso, permanecem intactos; a racialização da nação (negra) e a nacionalização da raça (negra) caminham lado a lado. Seja na negritude ou nas diferentes versões do pan-africanismo, a revolta não é contra o pertencimento africano a uma outra raça, mas contra o preconceito que designa a esta raça um status inferior.

No que diz respeito à tradição, o ponto de partida é a afirmação de que os africanos têm uma cultura autêntica que lhes confere um eu particular irredutível ao de qualquer outro grupo. A negação deste eu e desta autenticidade seria, assim, por si mesma, uma mutilação. Com base nesta singularidade, supóe-se que a África reinvente sua relação consigo mesma e com o mundo para pertencer a si mesma e escapar das obscuras regiōes e do opaco mundo aos quais a história a tem confinado. Por causa das vicissitudes da história, consideramos que a tradição ficou para trás. Daí a importân-

Estudos Afro-Asiáticos, Ano 23, no 1, 2001, pp. 183-209 
cia, para redescobri-la, da regressão e da imaginação, condições necessárias para superar a fase de humilhação e de angústia existencial causada pela histórica degradação do Continente.

A ênfase na afirmação de uma "interpretação africana" das coisas, na criação de esquemas próprios de autogestão, na compreensão de si mesmo e do universo, na produção de um saber endógeno - tudo isso levou a demandas por uma "ciência africana", por uma "democracia africana", por uma "língua africana". ${ }^{34}$ Esta ânsia de tornar a África única é apresentada como um problema moral e político, a reconquista do poder de narrar a própria história - e, portanto, a própria identidade - parecendo se tornar constitutivo de qualquer subjetividade. Em última análise, não se trata mais de afirmar o status de alter ego para os africanos no mundo, mas sim de declarar em alto e bom som sua alteridade.

Esta alteridade deve ser preservada a todo custo. Nas versões mais extremas do nativismo, a diferença, assim, é louvada, não como fonte de qualquer tipo de universalismo, mas como a inspiração para determinar os princípios e normas que governam as vidas dos africanos em completa autonomia e, se necessário, em oposição ao resto do mundo. Versões mais leves deixam aberta a possibilidade de se "trabalhar em direção ao universal" e de enriquecer a racionalidade ocidental, acrescentando a ela os "valores da civilização negra", "o gênio peculiar à raça negra”. Senghor chamou a isto de "rendez-vous du donner et recevoir" (o ponto de encontro entre o dar e o receber), do qual se supóe que um dos resultados seja a métissage de culturas.

Desde o século XIX, aqueles que afirmam que os africanos têm sua própria identidade cultural, que há uma autoctonia especificamente africana, resolveram encontrar uma denominação geral e um lugar onde ancorar sua prosa. O local geográfico foi a África tropical, definida como uma fronteira totalmente ficcional, cuja meta era abolir a fantasmática anatomia inventada pelos europeus e seguida por Hegel e outros. ${ }^{35}$ De alguma forma, os desunidos membros desta polis imaginária teriam que se unir novamente. O "corpo desmembrado" da história do Continente é, assim, reconstituído à luz do mito. Fez-se uma tentativa de localizar a africanidade em um lugar de características culturais específicas que se esperava que a pesquisa etnológica pudesse fornecer. Finalmente, a historiografia nacionalista se lançou à busca de relíquias perdidas dos antigos impérios africanos e do Egito faraônico (cf. Ki-Zerbo, 1972; Anta Diop, 1960; Obenga, 1973).

Estudos Afro-Asiáticos, Ano 23, no 1, 2001, pp. 184-209 
Na prosa do nativismo, assim como em algumas versões das narrativas marxistas e nacionalistas, uma quase equivalência é estabelecida entre raça e geografia. A identidade cultural deriva da relação entre os dois termos, tornando-se a geografia o lugar privilegiado no qual se supõe que as instituições e o poder da raça (negra) ganhem corpo. ${ }^{36} \mathrm{O}$ pan-africanismo, em particular, define o "nativo" e o "cidadão" a partir de sua identificação com o povo negro. Nesta mitologia, os negros tornam-se cidadãos não porque são seres humanos dotados de direitos políticos, mas por causa, tanto de sua cor, como do privilégio de sua autoctonia. As autenticidades territorial e racial confundem-se, e a África se torna a terra da gente negra. Já que a interpretação racial está na base de uma ligação cívica restrita, tudo o que não seja negro está fora de lugar, e, portanto, não pode reivindicar nenhuma forma de africanidade. Assim, os corpos espacial, racial e cívico são um só, cada um deles sendo testemunha de uma origem comunal autóctone, a partir da qual todo aquele que nasceu nesta terra ou partilha da mesma cor e dos mesmos ancestrais é um irmão ou uma irmã.

A idéia de uma africanidade não-negra é simplesmente impensável. Daí a impossibilidade de conceber, por exemplo, a existência de africanos de origem européia, árabe ou asiática - ou a noção de que os africanos podem ter múltiplas ancestralidades. Um dos resultados do comércio de escravos no Atlântico foi que hoje os negros vivem em locais os mais distantes. Como se pode inscrevê-los em uma nação definida racial e geograficamente, quando a geografia e a história os arrancaram do local de onde seus ancestrais vieram? Já que o espaço geográfico africano constitui a pátria natural do povo negro, aqueles que a escravidão levou devem "retornar à terra de [seus] pais... e descansarem em paz" (Blyden, 1967:124).

\section{O Espelho Despedaçado}

Acabamos de ver que os discursos africanos dominantes sobre o selfse desenvolveram dentro de um paradigma racista. Como discursos de inversão, eles retiram suas categorias principais dos mitos a que afirmam se opor, e reproduzem suas dicotomias (a diferença racial entre negro e branco; a confrontação cultural entre povos civilizados e selvagens; a oposição religiosa entre cristãos e pagãos; a convicção de que raça existe e está na base da moralidade e da nacionalidade). Eles estão inscritos em uma genealogia inte-

Estudos Afro-Asiáticos, Ano 23, no 1, 2001, pp. 185-209 
lectual baseada em uma identidade territorializada e em uma geografia racializada, em que o mito de uma polis racial obscurece o fato de que, se por um lado a rapacidade do capitalismo está na origem da tragédia, o fracasso africano em controlar sua própria ânsia predatória e sua própria crueldade também levou à escravidão e à subjugação (cf. Miller, 1988). Mais fundamentalmente, por trás do sonho da emancipação política e da retórica da autonomia, uma perversa operação foi estabelecida, cujo resultado apenas fortaleceu o ressentimento africano e sua neurose de vitimização.

De todas as tentativas feitas, durante o século XX, de romper com este sonho vazio e com este velho modo de pensar, duas são de particular interesse para nossa discussão. Em primeiro lugar estão os esforços para desconstruir a tradição (e assim a própria África) demonstrando-se que esta foi inventada. ${ }^{37}$ Deste ponto de vista, a África enquanto tal existe apenas na base do texto que a constrói como a ficção do Outro. Este texto, portanto, combina com o poder estruturante, de tal forma que um eu que reivindique falar por si mesmo, uma voz que seja autêntica, sempre corre o risco de ser condenada a expressar um discurso preestabelecido que mascara o seu próprio, censura-o ou o força à imitação.

Em outras palavras, a África só existe na base de uma biblioteca preexistente que intervém e se imiscui por toda parte, mesmo no discurso que afirma refutá-la, a tal ponto que, com relação à tradição e à identidade africanas, hoje é impossível distinguir o "original" da cópia, ou mesmo de um simulacro. ${ }^{38} \mathrm{O}$ mesmo pode ser dito sobre qualquer projeto que vise desenredar a África do Ocidente. Uma segunda via problematizou a identidade africana como uma identidade em formação (cf. Appiah, 1992). ${ }^{39}$ Deste ponto de vista, o mundo não é mais percebido como uma ameaça; pelo contrário, ele é imaginado como uma vasta rede de afinidades. Em contraste com as mitologias unanimistas, o ponto essencial é que todos podem imaginar e escolher o que o(a) torna africano.

Em grande medida, estas duas críticas levam a considerações metodológicas. Elas não vão ao fundo do problema: como devemos lidar com os espectros invocados pelos "nativistas" e os chamados "radicais", em suas respectivas tentativas de fundar uma identidade africana, bem na hora em que a imaginação e as práticas sociais destas mesmas identidades mostram que outras ordens de realidade estão sendo estabelecidas? Em outras palavras, como devemos conceber, criativamente e em sua heteronomia, os significantes abertos a qualquer significado que são a escravidão, o colonialismo e o apartheid? Filosoficamente, deve-se dar prioridade

Estudos Afro-Asiáticos, Ano 23, no 1, 2001, pp. 186-209 
àquilo que, na experiência africana de mundo, escapa à determinação e à idéia de uma história que ainda está sendo feita, e que se pode apenas seguir, ou repetir. Antropologicamente, à obsessão com a singularidade e a diferença, devemos opor a temática da igualdade. Para nos afastarmos do ressentimento e da lamentação sobre a perda de um 'nom propre', deve-se abrir um espaço intelectual para repensarmos aquelas temporalidades que estão, sempre simultaneamente, se ramificando em diversos futuros diferentes, e ao fazerem isso abrem caminho para a possibilidade de múltiplas ancestralidades. Sociologicamente, deve ser dada atenção às práticas cotidianas através das quais os africanos reconhecem o mundo e mantêm com ele uma familiaridade sem precedentes, ao mesmo tempo em que eles inventam algo que pertence tanto a eles, quanto ao mundo em geral. ${ }^{40}$

Deixem-me examinar, em breves linhas, algumas das questões propriamente filosóficas desprezadas pela crítica africana em sua reflexão sobre a escravidão, a colonização e o apartheid. A primeira diz respeito ao status do sofrimento na história, as várias maneiras com que as forças históricas infligem dano psíquico aos corpos coletivos, e as formas através das quais a violência molda a subjetividade. Aqui, a comparação com outras experiências históricas teria se mostrado apropriada. Tal seria o caso do Holocausto judeu. Sem dúvida, o Holocausto judeu, a escravidão e o apartheid representam formas de sofrimento genuínas. Todos são caracterizados por uma expropriação do eu por forças inomináveis. Em cada um dos três casos, estas forças assumem várias formas. Mas em todos eles a seqüência central é a mesma: à intoxicação orgiástica, representada pela administração da morte em massa, corresponde, como um eco, a colocação da vida entre dois quiasmas, de forma tal que o sujeito não sabe mais se está morto ou vivo. Um impulso destrutivo e uma desarticulação do eu e de toda a individualidade constituem o pano de fundo dionisíaco destes eventos separados no tempo, mas conectados pela mesma teia: a extrema desvalorização da vida. No fundo, estes três eventos testemunham contra a vida. Sob o pretexto de que a origem e a raça são critérios para qualquer tipo de avaliação, eles interditam a vida. Daí a pergunta: como se pode redimir a vida, ou seja, resgatá-la da incessante operação de sua negação?

A segunda questão tem a ver com o trabalho da memória, com a função do esquecimento, e com as modalidades da reparação. Será possível reunir a escravidão, a colonização e o apartheid em uma só memória, não a partir de uma distinção do tipo antes e

Estudos Afro-Asiáticos, Ano 23, no 1, 2001, pp. 187-209 
depois, ou passado e futuro, mas em seu poder genético: a partir da impossibilidade de um mundo sem Outros que eles revelam, e do peso da responsabilidade dos próprios africanos em face da tragédia - que não é o único elemento - em sua história? Aqui, a comparação entre as experiências africana e judia revela profundas diferenças. Contrariamente à memória judaica do Holocausto, não há, propriamente falando, nenhuma memória africana da escravidão. ${ }^{41} \mathrm{Ou}$, se há uma memória, ela é caracterizada pela fragmentação (cf. Borgomano, 2000). No melhor dos casos, a escravidão é experimentada como uma ferida cujo significado pertence ao domínio do inconsciente psíquico (feitiçaria). ${ }^{42}$ Os esforços conscientes em direção à recuperação da memória raramente escaparam à ambivalência que caracteriza gestos similares em outros contextos históricos (cf. Singleton, 1999; Bruner, 1996). ${ }^{43}$

Há duas razões para isto. Primeiro, entre a memória dos afro-americanos sobre a escravidão e aquela dos africanos do Continente, há uma zona de sombra que dá margem a um profundo silêncio: o silêncio da culpa e da recusa dos africanos em enfrentar o inquietante aspecto do crime que diretamente envolve sua própria responsabilidade. Pois o destino dos escravos negros na modernidade não é apenas resultado da vontade tirânica e da crueldade do Outro - mesmo que estas sejam bem conhecidas. O outro significante primitivo é a morte do irmão pelo irmão, "a elisão da primeira sílaba do nome da família” (Lacan) - em suma, a polis dividida. Ao longo da série de eventos que levaram à escravidão, há o rastro que os discursos africanos dominantes tentam apagar.

Isto é uma ablação significante, porque permite o funcionamento da ilusão de que as temporalidades da servidão e da miséria foram as mesmas em ambos os lados do Atlântico. Isto não é verdade (cf. Taylor, 1998). ${ }^{44}$ E é isto que evita que o trauma, a ausência e a perda sejam os mesmos de ambos os lados do Atlântico. ${ }^{45}$ Como resultado, o apelo à raça como a base política e moral da solidariedade sempre dependerá, em alguma medida, de uma miragem de consciência, já que os africanos continentais não repensaram o comércio escravista e as outras formas de escravidão, não apenas como uma catástrofe que se abateu sobre eles, mas também como fruto de uma história em que eles tiveram parte ativa na construção da forma pela qual lidaram uns com os outros. ${ }^{46}$

A segunda razão é de outra ordem. Em certas partes do Novo Mundo, a memória da escravidão é conscientemente reprimida pelos descendentes dos escravos africanos. O drama familiar que está na base desta tragédia, assim como, atualmente, a miséria de

Estudos Afro-Asiáticos, Ano 23, no 1, 2001, pp. 188-209 
suas existências, são constantemente negados. Para ser exato, esta negação não é equivalente ao esquecimento. Ela é simultaneamente uma recusa de reconhecer a própria ancestralidade e uma recusa a lembrar um ato que provoca sentimentos de vergonha. Sob tais condições, a prioridade não é realmente restabelecer contato consigo mesmo e com suas próprias origens. Nem é uma questão de restaurar uma relação plena e positiva consigo mesmo, posto que este eu foi danificado e humilhado para além de qualquer limite. Já que a narrativa da escravidão foi condenada a ser elíptica, um fantasma persegue e ronda o sujeito e inscreve em seu inconsciente o corpo morto de uma linguagem que deve ser constantemente reprimida. Pois para existir no presente, é considerado necessário esquecer o nome do pai no próprio instante no qual se afirma levantar a questão da origem e da filiação. Este é notavelmente o caso das Antilhas. ${ }^{47}$

A terceira questão é relativa ao simbolismo do exílio, e sem dúvida à metáfora do campo de concentração, que é utilizada para comparar a condição de escravidão com a condição judaica, assim como as relações entre raça e cultura na consciência moderna (Gilroy, 1999). Há algo de leviano e superficial nesta comparação. $\mathrm{Na}$ verdade, a imaginação judaica constantemente oscila entre uma pluralidade de mitos contrastantes e tensões não-resolvidas, mas produtivas: o mito da autoctonia, de um lado, e a realidade de um deslocamento forçado, do nomadismo e do ser errante, por outro; o fato empírico do deslocamento, por um lado, e a esperança de que a promessa seja cumprida e também do retorno, por outro; em suma, uma temporalidade em suspenso, na qual reside a visão dividida da diáspora e de Israel, em que a ausência de território de forma alguma significa a interrupção da continuidade judaica. E finalmente, para além da contingência, da fragmentação e do terror, há um livro, o Torá, um texto que constantemente está sendo escrito, reescrito e reinterpretado.

Para além da evidência das fraturas e da difração, a experiência dos escravos africanos no Novo Mundo reflete uma plenitude de identidade mais ou menos comparável, mesmo que as formas de sua expressão difiram, e mesmo que não haja nenhum livro. Tal como os judeus no mundo europeu, eles têm que "narrar a si mesmos" e "narrar o mundo", e lidar com este mundo a partir de uma posição na qual suas vidas, seu trabalho e seu modo de falar (langage) são parcamente legíveis, pois estão envolvidos em embalagens fantasmagóricas. Eles têm que inventar uma arte de existir em meio à espoliação, mesmo que agora seja quase impossível invocar

Estudos Afro-Asiáticos, Ano 23, no 1, 2001, pp. 189-209 
o passado e lançar sobre ele algum encantamento, exceto talvez nos termos sincopados de um corpo que constantemente é transformado de ser em aparência, de canção em música (Gilroy, 1993; Hall, 1992). Dito isto, a similaridade termina. Contrariamente ao Holocausto, nem filosoficamente, nem politicamente, nem culturalmente a experiência de escravidão dos negros no Novo Mundo e em outras partes do mundo foi interpretada de forma a trazer a possibilidade de fundar um telos universal.

A crítica marxista e nacionalista subestimou a grande variedade da experiência africana da conquista colonial. A historiografia recente tem mostrado que os africanos deram respostas diferentes à escolha a que os europeus os forçaram. As divisões sociais, durante o período do comércio escravista no Atlântico, tornaram-se mais agudas sob o teste da invasão européia. As novas formas de bem-estar adquiridas durante a fase do comércio de escravos, e logo após ela, fizeram adernar as constituições existentes. As duas principais religiões monoteístas, o islã e o cristianismo, questionaram as bases cosmológicas das sociedades locais. Enquanto a violência política e a extorsão se intensificaram durante a segunda metade do século XIX, o poder se libertou da responsabilidade política. As guerras pela sucessão local resultaram em uma crise de autoridade, ao mesmo tempo em que afetaram as relaçōes de poder e de obediência. Na maioria dos lugares, o avanço colonial em direção ao interior do Continente foi quase "uma efervescente revolta escrava" (Lonsdale, 1981).

De muitas formas, a colonização foi uma co-invenção. Ela tanto foi o resultado da violência ocidental, quanto do trabalho de seus auxiliares africanos em busca de lucro. Onde havia falta de colonos brancos para ocupar o território, os poderes coloniais geralmente recrutavam os negros para colonizarem seus próprios conterrâneos (congénères) em nome da nação metropolitana. Mais decisivamente, por mais "doentio" que possa parecer, o colonialismo como fenômeno mental e material exerceu uma forte sedução sobre os africanos. Esta atração foi tanto material, como moral e intelectual. Possibilidades ostensivas de mobilidade ascendente foram prometidas pelo sistema colonial. Se tais promessas realmente foram cumpridas, é algo que não está em questão. Como uma fábrica de ficções refratada e infinitamente reconstituída, o colonialismo gerou mútuas utopias e alucinações partilhadas pelos colonizadores e pelos colonizados. ${ }^{48}$

Os exemplos acima são suficientes para demonstrar que, através do recurso a certos expedientes, e por deixar de assinalar estas

Estudos Afro-Asiáticos, Ano 23, no 1, 2001, pp. 190-209 
questôes centrais sobre a vida, suas formas, suas possibilidades e sobre aquilo que a nega, a crítica africana, dominada pela economia política e pelo impulso nativista, tem, desde o começo, inscrito a busca pela identidade política em uma temporalidade puramente instrumental e de curto prazo. Quando surgiu a pergunta, no auge do colonialismo, sobre se a autogestão era possível, esta nunca foi aprofundada até a questão geral do "ser" e do "tempo", ou seja, da vida, mas sim estacionou na luta dos nativos para conseguirem o poder político e tomarem o aparelho de Estado. Na verdade, tudo se resume a uma perversa estrutura: a autoctonia. $O$ poder de arriscar a própria vida, ou seja, como Hegel sugere, a habilidade de acabar com a condição servil e renascer como sujeito do mundo, gradativamente foi perdendo lugar na prosa da autoctonia.

\section{Self, Polis e Cosmopolis}

Enfim, onde estamos hoje? Que formas de imaginar a própria identidade estão em desenvolvimento e que práticas sociais elas produzem? O que aconteceu com os tropos da vitimização, da raça e da tradição?

Em primeiro lugar, devo observar que a temática do antiimperialismo se exauriu. Isso não significa, no entanto, que o pathos da vitimização foi transcendido. Na verdade, este debate foi revivido durante os anos 80 e 90, na forma de uma crítica aos programas de ajuste estrutural e às concepções neoliberais sobre as relações entre o Estado e o mercado. ${ }^{40}$ Neste ínterim, a ideologia do pan-africanismo defrontou-se com a realidade dos Estados nacionais que, ao contrário do que tradicionalmente se falava, haviam se tornado menos artificiais do que se pensara. Mas, o mais significativo movimento é aquele que esboça uma junção entre o velho imaginário da "revolução" e do "anticolonialismo", a velha temática antiimperialista, com as teses nativistas. Fragmentos destes imaginários estão atualmente se combinando para oporem-se à globalização, para relançarem a metafísica da diferença, para reinvocarem a tradição e reviverem a utopia de uma africanidade que é a equivalência da negritude.

A temática da raça sofreu também grandes mudanças. Há algum tempo, o caso extremo da África do Sul (e outras colônias de assentamento) levava as pessoas a pensarem que a oposição polar entre brancos e negros resumia em si mesma toda a questão racial na África. Entretanto, os repertórios com base nos quais os imagi-

Estudos Afro-Asiáticos, Ano 23, no 1, 2001, pp. 191-209 
nários sobre a raça e o simbolismo do sangue se constituem, sempre se caracterizaram por sua grande variedade. Em um nível acima da oposição branco/negro, outras clivagens raciais sempre lançaram alguns africanos contra outros, não só aquelas mais visíveis (africanos negros versus africanos com ancestrais árabes, asiáticos, judaicos ou chineses; amharies versus oromos; tutsis versus hutus), mas também todas as outras que se referem tanto à existente panóplia de cores, como à participação de alguns grupos em projetos de dominação (africanos negros versus creoles, sírio-libaneses, berberes, tuaregs, afro-brasileiros, fulanis, mouros etc.).

$\mathrm{Na}$ verdade, não importa que definição se dê a tal noção: a unidade racial africana sempre foi um mito. Este mito atualmente está implodindo diante do impacto de fatores externos e internos conectados com as formas pelas quais as sociedades africanas estão ligadas a fluxos culturais globais. De um lado - mesmo que as desigualdades de poder e de acesso à propriedade, e mesmo que os estereótipos racistas e a violência permaneçam - a categoria "branco" não se refere mais aos mesmos significados que no tempo da colonização ou do apartheid. Embora a "condição branca" não tenha atingido um ponto de absoluta fluidez que a levaria a se destacar, de uma vez por todas, de qualquer referência ao poder, ao privilégio e à opressão, fica claro que a experiência dos africanos de origem européia continuou a se pluralizar através do Continente, e que as formas nas quais esta experiência é imaginada, não só pelos próprios brancos, mas também por outros, não são mais as mesmas. A diversidade desta experiência agora faz da identidade dos africanos de origem européia uma identidade contingente e situada. ${ }^{50}$

O mesmo pode ser dito sobre os luso-africanos, os africanos de origem asiática ou sírio-libanesa, mesmo que as condições históricas de sua transformação em cidadãos e suas posições no mapa social difiram daquelas referentes aos brancos e negros (Gregory, 1993). ${ }^{51}$ O caso dos africanos de origem árabe sugere transformaçôes de outro tipo. De um lado, as relações históricas e as influências entre o Maghreb mediterrâneo e a Âfrica sub-saariana são continuamente tanto reprimidas como transformadas em folclore. Oficialmente, a identidade maghrebiana é árabe-islâmica. Na realidade, ela provém de uma sincrética mistura de contribuições saharianas, berberes, árabes (da península) e mesmo judaicas e turcas. ${ }^{52}$ De outro lado, o islã tem servido como o idioma de uma matriz sociocultural dentro da qual a adesão à mesma fé e o pertencimento a uma única comunidade religiosa não afastam uma relação

Estudos Afro-Asiáticos, Ano 23, no 1, 2001, pp. 192-209 
senhor-escravo, como vemos na Mauritânia ou, bem mais ao Leste, na região árabe do Nilo (no Sudão em particular).

O simbolismo do sangue e das cores evolui por graus. Como em outras partes do mundo, a raça, a classe, a etnicidade e o gênero se interceptam e produzem, apesar de toda a ambivalência inerente a tais operaçôes, efeitos de violência. Em geral, as próprias formas de consciência racial estão mudando em todo o Continente. A produção de identidades raciais para além da oposição binária branco/negro cada vez mais opera de acordo com lógicas distintas, enquanto as velhas demarcações perdem seu aspecto mecânico e se multiplicam as oportunidades de transgressões. De várias formas, a instabilidade das categorias raciais demonstra que há muitos tipos de branquitude e de negritude. ${ }^{53}$

Deixe-me enfocar, por um instante, o tropo da tradição. $\mathrm{O}$ projeto de invocar a tradição é baseado em um conjunto de idéias e práticas sociais fragmentárias, ou seja, em um imaginário que retira dela referentes, tanto de fontes locais, como globais. Os vetores mais poderosos deste imaginário são os movimentos comunitários. Tais movimentos retiram seu poder da reabilitação das origens e do pertencimento, em que uma visão cosmopolita e universalista tende a enfatizar como sua característica essencial a habilidade de se afastar de qualquer tipo de essência. A idéia é que não há identidade que de alguma forma não leve a questôes relativas à origem e à ligação com elas, não importa que definição de origem seja dada e o quanto de ficção seja inerente a tal definição.

A différend de origem supostamente é o ponto de partida para se tornar consciente da própria identidade. De outro lado, toda identidade teria de ser traduzida em termos territoriais. Sob este ponto de vista, não há identidade sem territorialidade, que não seja a vívida consciência de ter um lugar e ser dono dele, seja por nascimento, por conquista ou pelo fato de ter se estabelecido em um dado local e este ter se tornado parte de sua auto-representação. A territorialidade par excellence é a localidade, ou seja, a casa, o pequeno espaço e o estado herdado, em que relações próximas e diretas são reforçadas pelo pertencimento a uma genealogia comum, à mesma matriz, real ou suposta, que serve como base para o espaço cívico. Funerais e cremações são algumas das formas principais de ritualizar o pertencimento ao espaço cívico representado pela casa (ver Arhin, 1994; Van der Geest, 2000). $\mathrm{Da}$ combinação de categorias ideológicas de pertencimento e de origem, de um lado, com categorias espaciais de território e localidade, de outro, emerge a cidadania, ou seja, a capacidade de usu-

Estudos Afro-Asiáticos, Ano 23, no 1, 2001, pp. 193-209 
fruir da casa, de excluir forasteiros deste usufruto, o direito à proteção e o acesso a uma gama de bens e recursos coletivos situados no espaço assim delimitado.

Além disso, os três idiomas de filiação, genealogia e herança podem, como tais, ser convertidos em recursos recicláveis no processo de globalização. Um dos veículos desta conversão é o léxico internacional dos direitos. Seja em relação à proteção do meio ambiente ou ao direito das minorias ou dos povos nativos, em todos os casos a questão é afirmar uma identidade ferida. A ferida supostamente teria levado a uma privação dos direitos específicos que a "comunidade" tenta recuperar usando o léxico internacional dos direitos. O outro veículo para invocar a tradição e reciclar identidades locais é o mercado. Isto ocorre particularmente no turismo e nas políticas relacionadas a questões de herança.

Mas se, como em qualquer outro lugar, a conexão com os fluxos da globalização passa (entre outras coisas) pela mercantilização de identidades sob o disfarce da tradição, uma das mediaçôes-chave entre o tempo global e as formas locais de reinvocar a tradição passa a ser a guerra ou, mais precisamente, o estado de guerra. Para além de seus aspectos puramente empíricos (a lógica da formação de milícias armadas, as relações entre a guerra e o lucro, a privatização da violência, o contrabando e o comércio de armas), o estado de guerra na África contemporânea poderia ser concebido como uma experiência cultural comum que molda identidades, do mesmo modo que a família, a escola e outras instituiçôes sociais. De uma forma ainda mais determinante, o estado de guerra se refere a regimes de subjetividade que devem ser resumidamente explorados aqui.

O primeiro deles se refere à entrada em uma zona de indistinção, ou seja, em um espaço fora da jurisdição humana, em que as fronteiras entre a regra da lei e o caos desaparecem, as decisões sobre a vida e a morte se tornam inteiramente arbitrárias e tudo se torna possível. ${ }^{54} \mathrm{Na}$ maioria das zonas de guerra na África, a entrada em uma zona de indistinção é marcada por um caráter sem precedentes de tortura, mutilação e assassinato em massa (cf. Brinkman, 2000). Progressivamente, a disseminação de fragmentos de terror vai ocupando espaços, explode relaçôes de referência temporal e enfraquece as possibilidades para os indivíduos de se reconhecerem como sujeitos integrados (ver Diop, 2000; Monenembo, 2000). A espetacularização do sofrimento que se segue serve apenas para reforçar o processo de constituição de memórias traumáticas. O horror das agressões ao corpo está ali para quem quiser

Estudos Afro-Asiáticos, Ano 23, no 1, 2001, pp. 194-209 
ver. Ossos humanos e pedaços de corpo derivam de corpos feridos, muitas vezes decepados, e de rostos mutilados. O trauma se tornou algo quase que permanente. A memória é fisicamente incorporada em corpos que permanentemente ostentam os sinais de sua própria destruição em uma paisagem geral de fragmentação e decadência econômica. Na maioria das instâncias, a vida tem tomado a forma de uma incessante jornada através do espaço. Alguém deixa um lugar e se estabelece em outro, apenas para ser desalojado dali novamente pelo terror, confrontado com circunstâncias imprevisíveis, e se estabelecer uma vez mais em outro lugar, onde puder. ${ }^{55}$

O segundo regime é a dimensão sacrificial da guerra. ${ }^{56}$ Como já foi demonstrado em outros lugares, em várias regiōes do Continente, a desconstrução material das referências territoriais existentes caminha lado a lado com o surgimento de economias de guerra (e da guerra como uma economia geral) nas quais violentos conflitos não mais implicam necessariamente em que aqueles que têm armas se opõem uns aos outros. Muitos conflitos parecem mais ser entre os que têm armas e os que não as têm. Nestes contextos, uma marcante desconexão entre as pessoas e as coisas se desenvolve, em que o valor das coisas se sobrepõe ao valor das pessoas. As formas resultantes de violência têm como sua principal meta a destruição física das pessoas (massacres de civis, genocídios, vários tipos de mutilação e morte) e a exploração primária dos recursos minerais (cf. Mbembe, 2000). A maioria destes eventos se baseia na idéia da história como processo sacrificial.

Aqui, a palavra "sacrifício" tem dois sentidos: o auto-sacrifício (colocar a própria vida à disposição do outro, se deixar morrer por uma causa) e o assassinato em massa (a aniquilação física de incontáveis vidas humanas). De um lado, o auto-sacrifício implica em que alguém vai matar outros seres humanos que são identificados como sendo "o inimigo". Este alguém aceita a idéia de que pode ser morto neste processo. Este alguém acredita que neste tipo de morte se encontra a essência da vida. De outro lado, o massacre constitui o mais grandioso signo tanto de soberania como do que Bataille chama de dispêndio (Bataille, 1967). Mais do que qualquer outra coisa, isto marca o limite do princípio de utilidade - e portanto da idéia de preservação - das vidas humanas. É a soberania da perda, através da espetacular destruição e do derramamento de sangue dos seres humanos.

Os cadáveres reais, as coisas mortas, tudo parece congelado e solto no espaço. Emergem dúvidas como estas: será que aquelas coisas aparentemente animadas, que parecem vivas, o estão real-

Estudos Afro-Asiáticos, Ano 23, no 1, 2001, pp. 195-209 
mente, ou serão elas apenas cadáveres figurativos daqueles que estiveram vivos e agora são um espelho despedaçado na fronteira da loucura e da abjeção ? $^{57}$ A função desta violência dionisíaca não é estarrecer ou mesmo enlouquecer ${ }^{58}$. Também não é simplesmente parte de um processo de manumissão e abatimento. Para ser exato, ela não é mais uma questão de se apropriar do Outro ou de animalizá-lo ou de torná-lo uma mercadoria, como ocorreu durante o período do comércio de escravos no Atlântico, ou logo após ele. É uma questão de abolir de uma vez por todas a própria idéia de uma divida em relação à vida (cf. Mbembe, no prelo).

Mas no ato que consiste em matar inumeráveis vítimas sacrificiais, o agente do massacre também busca transcender a si próprio e inventar um novo eu. Tremendo de embriaguez, ele ou ela se transforma em uma espécie de obra de arte formada e esculpida pela crueldade. É neste sentido que o estado de guerra se torna parte das novas práticas africanas em torno do eu. Através da guerra, o sujeito africano transforma sua própria subjetividade e produz algo que não pertence ao domínio de uma identidade perdida que deve a todo custo ser fundada novamente, mas sim algo radicalmente diferente, algo que pode mudar, e cuja teoria e vocabulário ainda estão por serem inventados (ver Kourouma, 2000).

Em terceiro lugar, o estado de guerra se relaciona a dois outros determinantes centrais que estiveram presentes na experiência da escravidão e do apartheid: a vida e a propriedade. A vida, no sentido de que o estado de guerra autoriza o poder, e mesmo a força bruta, a ser exercido de forma extrema e absoluta. Como resultado, o cálculo que governa as práticas culturais e políticas não têm mais como seu objetivo a sujeição dos indivíduos nem o gozo do poder sobre a vida em si mesmo. Sua função é abolir qualquer idéia de ancestralidade, e portanto qualquer dívida em relação a um passado. Surge aí, então, um imaginário original sobre a soberania cujo campo de exercício é a vida em sua generalidade. Esta última pode ser sujeita a uma morte empírica, ou seja, biológica. Mas ela pode também ocorrer "à prestação", tanto quanto o podem as coisas, em uma economia geral na qual massacres e carnificinas são então relacionados da mesma forma que, no dogma marxista, o capital, o trabalho e a mais-valia costumavam se relacionar.

A outra forma de instituir uma imaginação - através da qual a junção entre o local e o cosmopolita se efetive - é o estado de religião (l'état de religion). Para a maioria das pessoas, a relação com a soberania divina agora serve como principal fonte de significados, mesmo que as formações discursivas que retiram seu simbolismo

Estudos Afro-Asiáticos, Ano 23, no 1, 2001, pp. 196-209 
central da religião estejam longe de ser homogêneos. Em quase todo lugar, as práticas em curso a partir das quais o poder divino é mimetizado ou performatizado se ligam ao processo de reinvenção do eu e da polis - esta, em seu duplo sentido: a polis terrena e a celestial (o reino). Esta categorização não reflete apenas uma divisão entre este mundo e o do além. Ela também indica como o eu surge a partir da interação entre o mundo dos seres existentes e daquilo que não pode ser a isto reduzido. Através de rituais específicos e de celebrações de vários tipos, a vida religiosa vai se tornando o lugar onde as redes de uma nova relação, não biológica, entre os membros de uma família ou mesmo um oecumene se formam, ao mesmo tempo em que as noçóes de soberania divina e patronato vão sendo transformadas e novos dogmas emergem.

Mais fundamentalmente, o desenvolvimento de um novo imaginário religioso se baseia na mobilização de três formações ideo-simbólicas cuja ligação com concepções contemporâneas é evidente: a noção de carisma (que autoriza a prática da profecia e da declaração oracular, da possessão e da cura); os registros sacrificiais (mortes e funerais); e finalmente os domínios do milagroso (ou seja, a crença de que tudo é possível). O carisma, em particular, se refere a dois fatos aparentemente contraditórios. De um lado, ele representa o zênite da individualidade, assim como da experiência compartilhada. Embora se suponha que nem todo membro da congregação seja tocado pelo dom da profecia, per se, cada um deles todavia tem acesso livre à mesma fonte de poder: a graça divina. Esta última é expressa através de capacidades tais como a cura, a vidência de espíritos, a capacidade de falar em várias línguas (cf. Falco, 1999). De outro lado, o carisma representa a manutenção de um poder e de uma autoridade distinta e autônoma, benevolamente exercida a serviço das necessidades de uma comunidade. O exercício desta autoridade coloca o taumaturgo em uma relação hierárquica com aqueles que não estão envolvidos com a mesma magia, o mesmo saber. Tenta-se gerenciar o "mundo real" na base da convicção de que toda simbolização se refere, em primeiro lugar, a um sistema invisível, do universo mágico, pertencendo o presente, acima de tudo, a uma seqüência que sempre dá margem a algo diferente.

A última mudança cultural importante tem a ver com a questão do desejo e do consumo imaginário em uma economia de carências e escassez. ${ }^{59}$ Tanto as fontes como os vetores desta imaginação são, em larga medida, os mesmos encontrados em qualquer outro lugar do mundo. Mas, um em particular requer nossa atenção. É aquele que tem a ver com tudo o que afeta a economia dos

Estudos Afro-Asiáticos, Ano 23, no 1, 2001, pp. 197-209 
bens desejados, que são conhecidos, que podem por vezes serem vistos, que se quer aproveitar, mas ao qual nunca se terá acesso. Há um elemento de ficção nestes bens desejados. Nesta situação, o que é decisivo na formação das subjetividades é talvez o fato de que o fluxo de trocas não ocorre. Onde a aquisição e o consumo de bens desejados, porém não acessíveis, são problemáticos, outros regimes de subjetividade se desenvolvem.

Onde a carência e a escassez prevalecem, a apropriação de bens desejados muitas vezes se apresenta através da pilhagem, do gozo violento, ou no reino fantasmático (ver Comaroff e Comaroff, 1999). As fantasias, portanto, se direcionam a objetos puramente imaginários. Os poderes de imaginação são estimulados, intensificados pela própria inacessibilidade dos objetos de desejo. As práticas do roubo, as várias formas de atividade mercenária e os diferentes registros de falsificação se baseiam em uma economia que mobiliza paixóes tais como cobiça, inveja, ciúme e a sede de conquista. O curso da vida é associado a um jogo de acaso (uma loteria) na qual o horizonte existencial temporal é colonizado pelo presente imediato e por cálculos prosaicos de curto prazo. $\mathrm{Na}$ engrenagem geral de captação dos fluxos da troca global, os rituais de ostentação se desenvolvem. Eles consistem em mimetizar os grandes significados do consumo global.

\section{Conclusão}

Tentativas de definir a identidade africana de forma simples e clara têm ao longo do tempo geralmente falhado. Outras tentativas parecem estar tendo o mesmo fim, já que a crítica das imaginações africanas sobre o self e o mundo permanece presa dentro de uma concepção de tempo como espaço e de identidade como geografia. Desta confusão resultou uma interdição massiva das noções gêmeas de "universalismo" e de "cosmopolitismo", e uma celebração da autoctonia, ou seja, de um eu entendido como sendo tanto vítima como mutilado. Uma das implicações principais de tal compreensão de tempo e de sujeito é que o pensamento africano passou a conceber a política ou através de um resgate de uma natureza essencial, porém perdida (a libertação da essência) ou como um processo sacrificial.

Para ser exato, não há nenhuma identidade africana que possa ser designada por um único termo, ou que possa ser nomeada por uma única palavra; ou que possa ser subsumida a uma única

Estudos Afro-Asiáticos, Ano 23, no 1, 2001, pp. 198-209 
categoria. A identidade africana não existe como substância. Ela é constituída, de variantes formas, através de uma série de práticas, notavelmente as práticas do self (cf. Biaya, 2001, e no prelo; ver, também, Malaquais, no prelo). Tampouco as formas desta identidade e seus idiomas são sempre idênticos. E tais formas e idiomas são móveis, reversíveis, e instáveis. Isto posto, elas não podem ser reduzidas a uma ordem puramente biológica baseada no sangue, na raça ou na geografia. Nem podem se reduzir à tradição, na medida em que o significado desta última está constantemente mudando (cf. Hamilton, 1998).

Mas aquela retórica, agora tão familiar e clichê, da não-substancialidade, da instabilidade e da indeterminação é apenas mais uma forma inadequada de lidar com as imaginações africanas sobre o eu e o mundo (ver Simone, no prelo; Diouf, 2000; MacGaffey e Bazenguissa-Ganga, 2000). Não é mais suficiente afirmar que apenas um eu africano dotado de uma capacidade narrativa de síntese, ou seja, capaz de gerar tantas histórias quantas forem possíveis a partir de quantas vozes forem possíveis, pode afirmar a discrepância e a multiplicidade de normas e regras interligadas características de nossa época. Talvez um passo além deste círculo seja reconceitualizar a própria noção de tempo em sua relação com a memória e a subjetividade. ${ }^{60}$ Já que o tempo em que vivemos é fundamentalmente fraturado, o próprio projeto de um resgate essencialista ou sacrificial do eu está, por definição, fadado ao fracasso. Apenas as diversas (e muitas vezes interconectadas) práticas através das quais os africanos estilizam sua conduta podem dar conta da densidade da qual o presente africano é feito.

\section{Notas}

1. Para um panorama geral, cf. Chukwudi Eze (1997).

2. Não há como negar o fato de que uma distinta filosofia africana emergiu a partir da interseção das práticas religiosas africanas com a interrogação sobre a tragédia humana. Em sua maioria, este questionamento foi governado por narrativas sobre a perda. A mediação africana entre a soberania divina e as histórias do povo africano não resultou em uma reflexão filosófico-teológica suficientemente sistematizada para situar o infortúnio humano e o erro em uma perspectiva teórica singular. Apesar disso, ver tentativas neste sentido, de Eboussi-Boulaga (1981); Éla (1981, 1988); Mudimbe (1997).

3. Para ser exato, as duas correntes de pensamento não têm uma única teoria sobre a identidade, a política ou a cultura. Para críticas diferentes, ver Dieng (1979); Jewsiewicki (1985); Mudimbe (1994:41-46; 1991:166-191). Pode-se ir mais longe na ar-

Estudos Afro-Asiáticos, Ano 23, no 1, 2001, pp. 199-209 


\section{Achille Mbembe}

gumentação, afirmando-se que em sua tentativa de reconceitualizar o problema do sujeito, o feminismo africano não alterou fundamentalmente a compreensão marxista, nacionalista ou nativista africanas dominantes a respeito da subjetividade ou dos conceitos da intencionalidade humana. Ver, por exemplo, Mama, Imam \& Sow (1997); Amadiume (1997).

4. Discutindo tal questão, seja em termos de "alienação", ou de "desrazão", a crítica francesa tem conceitualizado de forma mais profunda este processo. Ver, em particular, Fanon (1967); Hamidou Kane (1961); Eboussi-Boulaga (1977, 1981).

5. Isto se aplica particularmente aos estudos anglófonos sobre economia política marxista, antropologia e história. Por vezes estes estudos também repousam em teses nacionalistas e dependentistas. Como exemplos, ver Aké (1981); Rodney (1981) e, de uma forma mais geral, Amin (1973).

6. Sobre a problemática da escravidão e da reparação, ver Ajayi (2000). Para interpretações mais sutis e sofisticadas da escravidão e de seu impacto, cf. Patterson (1982). Sobre a "dispersão" vista a partir do outro lado do Atlântico, cf. Gilroy (1993).

7. Para ser exato, foram feitas tentativas ocasionais. $\mathrm{O}$ apartheid tem sido tema de constante interpretação bíblica. Ver, entre outros, Boesak (1984); Tutu (1984). A colonização também tem sido tema de tais interpretações. Ver, por exemplo, Bimwenyi-Kweshi (1981); Éla (1980, 1985).

8. Ver, por exemplo, Mkandawire \& Soludo (1999).

9. Ver, por exemplo, Depelchin (1983).

10. Esta tendência tomou forma durante o último quarto do século $\mathrm{XX}$, em um grande número de produções ideológicas de instituições nacionais, como a Universidade de Dar-es-Salam (Tanzânia) nos anos 60 e 70, e outras instituiçôes continentais tais como o Conselho para o Desenvolvimento da Pesquisa em Ciência Social na África (CODESRIA) além de organizações sub-regionais tais como a Southern African Political Economy Series (SAPES) em Harare (Zimbabwe). Para uma teorização a respeito, ver Aké (1981a, 1978).

11. Ver a crítica ideológica dos programas de ajuste estrutural e da contínua dependência conceitual a partir de um paradigma desenvolvimentista em Mkandawire \& Olukoshi (1995).

12. Ver, sobre movimentos sociais, Mamdani \& Wamba-dia-Wamba (1995). Sobre a crítica populista da democracia liberal, ver Aké (2000); Shivji $(1989,1988)$.

13. Ver, por exemplo, Mamdani (1997); Shivji (1976).

14. Um exemplo recente é Mamdani (1996, 1976).

15. Ver, por exemplo, Zeleza $(1993,1997)$.

16. Para ser exato, o Iluminismo não tem uma única teoria racial. No entanto, a maioria de seus escritores trabalhou dentro de um único universo de discursos. Como demonstra Paul Gilroy, o extenso debate sobre se os "negros" deveriam ser admitidos como membros da família humana foi central na formação da episteme moderna. Ver Gilroy (1998:847). Ver, também, Buck-Morss (2000), e, de forma mais geral, Chukwudi Eze (1997).

17. Sobre a centralidade do corpo na filosofia ocidental e seu status como a unidade ideal do sujeito, o locus do reconhecimento de sua identidade, cf. Merleau-Ponty (1945:81-234). Sobre o "peso" do corpo do colonizado, ver Fanon (1967:110-113).

Estudos Afro-Asiáticos, Ano 23, no 1, 2001, pp. 200-209 
18. Sobre esse ponto e tudo o que o precede, cf. Grandmaison (1992); Pluchon (1984); Montesquieu (1979); Voltaire (s/d), Kant (1965).

19. A mais completa forma institucional desta economia da alteridade é o sistema de apartheid,, no qual as hierarquias são biológicas em seu caráter. Sua versão reduzida é a "indirect rule": uma forma não muito custosa de dominação que, nas colônias britânicas, tornava possível exercer a autoridade sobre os nativos de maneira regular, com poucos soldados, mas utilizando as paixões e vícios dos nativos. Cf. Mair (1936); Lugard (1980).

20. Isto era feito apesar do fato de que a "tradição" variava radicalmente de lugar para lugar. Como foi o caso em outros locais, a "tradição" tornou-se o tropo para uma sociedade considerada fora da história, sem indivíduos. Ela poderia, de agora em diante, ser reproduzida através da força da lei. Sobre experiências similares em outras partes do mundo colonizado, ver Dirks (1997).

21. Na prática, os novos sujeitos políticos criados pela política da assimilação foram considerados como sendo uma reprodução homogênea do sujeito metropolitano. Christopher Miller afirma, corretamente, que a "teoria e a prática da assimilação enfatizavam a continuidade com a metrópole e a reprodução de 'seus' valores, ao mesmo tempo ignorando ou negando a ruptura verdadeiramente profunda que os sujeitos coloniais estavam experimentando em relação às suas próprias culturas" (cf. Miller, 1998:122). Como Fanon tornará claro, a barreira entre o assimilée a essência nacional francesa continuou sendo a raça, com a biologia restringindo o grau de nacionalidade francesa acessível ao colonizado (cf. Fanon, 1967:cap. 5).

22. Mesmo quando o postulado da igualdade entre os seres humanos é admitido, a colonização é, por vezes, justificada em nome da "civilização" (cf., entre outros, Tocqueville, 1988). Sobre as ambigüidades das políticas de assimilação francesas, ver Conklin (1998).

23. Cf. os ensaios reunidos em Wilson (1969).

24. Cf., por exemplo, Condorcet (1849).

25. Ver, por exemplo, os textos reunidos em Bragança e Wallerstein (1982).

26. Ver Mafeje 2000. Para visões diferentes, cf., no mesmo volume, as contribuições de Mwangi \& Zaiman (2000); Éboussi-Boulaga (2000); Ben Romdhane (2000).

27. Isto é algo que a linguagem comum reconhece plenamente, mas que o léxico marxista africano evita nomear. Ver, por exemplo, Wamba-dia-Wamba (1998).

28. Cf. a importância deste tema em Fanon (1952). Ver também Césaire (1950) e, de forma geral, a poesia de Léopold Sédar Senghor.

29. Ver, por exemplo, Anta Diop (1967).

30. Sobre isto, ver as últimas páginas de Fanon (1952).

31. Esta é a tese de L. S. Senghor (1964, 1977).

32. Comparar com a problemática da raça nos Estados Unidos, tal como discutida em Mills (1998) e Gordon (1997).

33. Cf. a crítica de Kwame Anthony Appiah dos textos de Alexander Crummel e W. B. Dubois em Appiah (1992:caps.1-2). Ver, também, Appiah (1986/87).

34. Sobre estes debates, cf. Nyerere (1968); Wiredu (1997, 2000); Hountondji (1997); Gyekye (1996, 1998); Ngugi wa Thiong'o (1986).

35. Cf. a geografia da África proposta por Hegel (1953).

Estudos Afro-Asiáticos, Ano 23, no 1, 2001, pp. 201-209 


\section{Achille Mbembe}

36. Ironicamente, encontramos o mesmo impulso e o mesmo desejo de fundir raça e geografia nos escritos racistas dos colonos brancos da África do Sul. Para detalhes sobre este assunto, cf. Coetzee (1988).

37. Em seu estudo sobre as bases do discurso sobre a África, Mudimbe comenta que "os intérpretes, assim como os analistas africanos, têm usado categorias e sistemas conceituais que dependem de uma ordem epistemológica ocidental. Mesmo nas descrições mais explicitamente 'afrocêntricas', os modelos de análise, explicitamente ou de forma implícita, consciente ou inconscientemente, se referem à mesma ordem”. Cf. Mudimbe (1988).

38. Para um estudo de caso, cf. Hamilton (1998).

39. Em estudo posterior, Appiah denuncia a falta de profundidade das posiçóes nacionalistas, frisa a possibilidade de uma dupla ancestralidade, e se filia ao "cosmopolitismo liberal". Cf. Appiah, (1997).

40. Há poucos anos, uma série de estudos têm mostrado como, acima das afirmações de africanidade, os africanos têm constantemente negociado novas posiçôes nos espaços entre as culturas e têm rompido os signos de identidade e de diferença. Cf., entre outros, Barber (1997); Nuttall e Michael (2000); Haynes (2000). Para dois estudos de caso sobre os complexos entrelaçamentos das chamadas tradiçōes intelectuais globais com as "tradicionais", cf. Bhekizizwe (2000) e Newell (2000).

41. Sobre a memória judaica, ver, entre outros estudos, LaCapra (1998) e Yerushalmi (1982). Para uma crítica filosófica, cf. Ricoeur (2000).

42. Cf., por exemplo, Shaw (1997). Cf., também, o número especial "Route et traces des esclaves", Diogène, no 179, 1997.

43. No contexto pós-apartheid, cf. a descrição de "township tours", de Steven Robins (2000).

44. Comparar com Hallward (1998).

45. Sobre o status destas categorias, em geral, e seu papel na consciência judaica, em particular, cf. LaCapra (1998).

46. Lovejoy e Richardson (1999) mostram como os comerciantes africanos de escravos e os mercadores britânicos adaptaram a instituição local da "penhora" como forma de assegurar o crédito (ou os bens) contra a entrega de escravos. Para uma discussão geral sobre a penhora humana na África, cf. Falola e Lovejoy (1994).

47. Sobre tais questôes, cf. Maragnes, "L'identité et le désastre. Origine et fondation", Portulan, no 98, (s/d.), um número especial dedicado à "Mémoire juive, mémoire nègre. Deux figures du destin”.

48. Cf. a leitura que Françoise Vergès faz de Fanon (1997).

49. Ver, por exemplo, Mkandawire e Soludo (1999).

50. Compare, por exemplo, Smith (1997), Kock (1998) e Krog (1998). De forma mais geral, ver Nuttall, "Subjectivities of Whiteness" (no prelo).

51. Cf., também, Yap e Mang (1996), Mark (1999).

52. Cf. "Africanité du Maghreb", Africultures, nº 13, 1998; e o número especial "Afrique noire et monde arabe: continuités et ruptures", Cahiers des Sciences Humaines, n 16 , 2000.

53. Cf., em outro contexto, Sansone (1997).

54. Sobre estas discussões, cf. Edkins (2000).

Estudos Afro-Asiáticos, Ano 23, no 1, 2001, pp. 202-209 
55. Aqui, inspirei-me em Daniel Pécaut, "Configurations of space, time, and subjectivity in a context of terror: The Colombian example" (2000).

56. Esta é uma dimensão que também se encontra nas práticas autóctones, e que as religiôes monoteístas apenas acentuaram. Sobre as práticas autóctones, ver Law (1985); sobre questões mais gerais, ver Milbank (1995).

57. Sobre "cadáveres" e "abjeção", ver Kristeva (1982).

58. Sobre o caráter dionisíaco do processo, ver Memel-Fotê (1993).

59. Comparar com Sergei Oushakine, "The quantity of style: imaginary consumption in the New Russia" (2000).

\section{Referências Bibliográficas}

AJAYI, Ade (2000), "Pan-Africanism and the Struggle for Reparations". In T. Falola (ed.), Tradition and Change in Africa: The Essays ofJ.F. Ade Ajayi. Trenton, NJ, Africa World Press.

_ (2000), "The Atlantic Slave Trade and Africa". In T. Falola (ed.), Tradition and Change in Africa: The Essays of J.F. Ade Ajayi. Trenton, NJ, Africa World Press.

AKÉ, Claude (1978), Revolutionary Pressures in Africa. London, Zed Press.

(1981), A Political Economy of Africa. Harlow, Longman.

_ (1981a), Social Science as Imperialism: The Theory of Political Development. Ibadan, Ibadan University Press.

_ (2000), The Feasibility of Democracy in Africa. Dakar, CODESRIA.

AMADIUME, Ifi (1997), Re-inventing Africa: Matriarchy, Religion, and Culture. London, Zed Books.

AMIN, Samir (1973), Le Développement Inégal. Essai sur les Formations Sociales du Capitalisme Périphérique. Paris, Éditions de Minuit.

ANTA DIOP, Cheickh (1967), Antériorité des Civilisations Nègres. Mythe ou Vérité Historique? Paris, Présence Africaine.

_ (1960). L'Unité Culturelle de l'Afrique Noire. Paris, Présence Africaine.

APPIAH, Kwame Anthony (1997), "Cosmopolitan Patriots". Critical Inquiry, no 23, pp. 617-639.

ARENDT, Hannah (1987), La Tradition Cachée. Le Juif comme Paria (tr. Sylvie Courtine-Denamy). Paris, Christian Bourgois Éditeur.

ARHIN, Kwame (1994), "The Economic Implications of Transformations in Akan Funeral Rites”. Africa, vol. 64, no 3, pp. 307-321.

AZIKIWE, Nnamdi (1969), Renascent Africa. London, Cass.

BAER, Yitzhak F. (2000), Galout. L'imaginaire de l'Exil dans le Judaïsme (tr. Marc de Launay). Paris, Calmann-Lévy;

BARBER, Karin (ed.) (1997), Readings in African Popular Culture. London, James Currey.

BATAILle, Georges (1967), La Part Maudite, Précédé de la Notion de Dépense. Paris, Éditions de Minuit.

BEN ROMDHANE, Mahmoud (2000), "A Word from a Non Black African”. CODESRIA Bulletin, $\mathrm{n}^{\circ} 1$.

Estudos Afro-Asiáticos, Ano 23, no 1, 2001, pp. 203-209 


\section{Achille Mbembe}

BHEKIZIZWE, Peterson (2000), Monarchs, Missionaries \& African Intellectuals. African Theatre and the Unmaking of Colonial Marginality. Johannesburg, Witwatersrand University Press.

BIAYA, Tshikala K. (2001), "Eroticism in Senegal and the Art of Ousmane Dago". Public Culture, vol. 12, no 3, pp. 707-720.

_ (no prelo), "Les Plaisirs de la Ville: Masculinité, Féminité et Sexualité à Dakar, 1997-2000".

BIMWENYI-KWESHI, Oscar (1981), Discours Théologique Négro-africain. Problèmes de Fondements Paris, Présence Africaine.

BLYDEN, Edward W. (1967), Christianity, Islam and the Negro Race. Edinburgh, Edinburgh University Press.

BOESAK, Alan (1984), Black and Reformed: Apartheid, Liberation and the Calvinist Tradition. New York, Orbis Books.

BORGOMANO, Madeleine (2000), "La Littérature Romanesque d'Afrique Noire et l'Esclavage. 'Une Mémoire de l'Oubli'?'. In M-C Rochmann (ed.), Esclavage et Abolitions. Mémoires et Systèmes de Représentation. Paris, Karthala.

BRAGANÇA, Aquino de \& WALLERSTEIN, Immanuel (eds.) 1982), The African Liberation Reader. London, Zed Press, 3 vols.

BRINKMAN, Inge (2000), "Ways of Death: Accounts of Terror from Angolan Refugees in Namibia”. Africa, vol. 70, no 1, pp. 1-24.

BRUNER, E. (1996), "Turism in Ghana: The Representation of Slavery and the Return of the Black Diaspora”. American Anthropologist, no 98, pp. 290-304.

BUCK-MORSS, Susan (2000), "Hegel and Haiti". Critical Inquiry, vol. 26, no 4, pp. 821-865.

CABRAL, Amilcar (1970), Revolution in Guinea: Selected Texts. New York, Monthly Review Press.

CÉSAIRE, Aimé (1950), Discours sur le Colonialisme. Paris, Présence Africaine.

CHUKWUDI EZE, Emmanuel (ed.) (1997), Postcolonial African Philosophy. A Critical Reader. London, Blackwell.

(ed.) (1997), Race and Enlightenment. A Reader. Cambridge, MA, Blackwell.

COETZEE, John M. (1998), White Writing. On the Culture of Letters in South Africa. New Haven, Yale University Press.

COMAROFF, Jean \& COMAROFF, John (1999), "Occult Economies and the Violence of Abstraction: Notes From the South African Postcolony". American Ethnologist, vol. 26, n², pp. 279-303.

CONDORCET (1849), "Réflexions sur l'Esclavage des Nègres”. In Oeuvres. Paris, Firmin-Didot.

CONKLIN, Alice L. (1998), A Mission to Civilize: The Republican Idea of Empire in France and West Africa, 1895-1930. Stanford, CA, Stanford University Press.

DE KOCK, Eugene (1998), A Long Night's Damage: Working for the Apartheid State. Saxonwold, Contra.

DELEUZE, Gilles (1985), Cinéma 2. L'Image-Temps. Paris, Éditions de Minuit.

DEPELCHIN, Jacques (1983), "African Anthropology and History in the Light of the History of FRELIMO”. Contemporary Marxism, no 7, pp. 69-88.

Estudos Afro-Asiáticos, Ano 23, no 1, 2001, pp. 204-209 
DIENG, Amady A. (1979), Hegel, Marx, Engels et les Problèmes de l'Afrique Noire. Dakar, Sankoré.

DIOP, Boubacar B. (2000), Le Livre des Ossements. Paris, Présence Africaine.

DIOUF, Mamadou (2000), "The Senegalese Murid Trade Diaspora and the Making of a Vernacular Cosmopolitanism”. Public Culture, vol. 12, no 3, pp. 679-702.

DIRKS, Nicholas B. (1997), "The Policing of Tradition: Colonialism and Anthropology in Southern India”. Comparative Studies in Society and History, vol. 39, no 1, pp. 182-212.

EBOUSSI-BOUlAGA, Fabien (1977), La crise du Muntu. Paris, Présence Africaine.

_ (1981), Christianisme sans fétiche. Révélation et domination. Paris, Présence Africaine.

_ (2000), "Race, Identity and Africanity". CODESRIA Bulletin, no 1.

EDKINS, Jenny (2000), "Sovereign Power, Zones of Indistinction, and the Camp". Alternatives, no 25 , pp. 3-25.

ÉLA, Jean-Marc (1981), Le Cri de l'Homme Africain. Paris, L'Harmattan.

(1988), Ma Foi d'Africain. Paris, Karthala.

FALCO, Raphael (1999), "Charisma and Tragedy. An Introduction”. Theory, Culture and Society, vol.16, no 3 .

FALOLA, Toyin \& LOVEJOY, Paul E. (eds.) (1994), Pawnship in Africa: Debt Bondage in Historical Perspective. Boulder, CO, Westview Press.

FANON, Frantz (1952), Peau Noire, Masques Blancs. Paris, Seuil.

(1967), Black Skin, White Masks. New York, Grove Press.

FERGUSON, James (2000), Expectation of Modernity. Berkeley, University of California Press.

GILROY, Paul (1993), The Black Atlantic: Modernity and Double Consciousness. Cambridge, MA, Harvard University Press.

_ (1998), "Race Ends Here". Ethnic and Racial Studies, vol. 21, no 5.

_ (1999), "Between Camps: Race and Culture in Postmodernity. An Inaugural Lecture". Economy and Society, no 28, pp. 183-197.

GOLDBERG, Sylvie Anne (2000), La Clepsydre. Essai sur la pluralité des temps dans le judä̈sme. Paris, Albin Michel.

GORDON, L. R. (ed.) (1997), Existence in Black. An Anthology of Black Existential Philosophy. New York, Routledge.

GRANDMAISON, Olivier Le Cour (1992), Les Citoyennetés en Révolution (1789-1794). Paris, Presses Universitaires de France.

GREGORY, R. G. (1993), South Asians in East Asia. An Economic and Social History, 1890-1980. Boulder, CO, Westview Press.

GUIRAL, P. \& TEMIME, E. (eds.) (1977), L’Idée de Race dans la Pensée Politique Française Contemporaine. Paris, Éditions du CNRS.

GYEKYE, Kwame (1996), African Cultural Values: An Introduction. Accra, Sankofa Publishing Company.

_ (1998), Tradition and Modernity: Philosophical Reflections on the African Experience. New York, Oxford University Press.

HALL, Stuart (1992), "What is this "Black" in Black Popular Culture?". In G. Dent (ed.), Black Popular Culture. Seattle, WA, Bay Press.

Estudos Afro-Asiáticos, Ano 23, no 1, 2001, pp. 205-209 


\section{Achille Mbembe}

HALLWARD, Peter (1998), "Edouard Glissant between the Singular and the Specific". The Yale Journal of Criticism, vol. 11, no 2, pp. 441-464.

HAMIDOU KANE, Cheickh (1961), L'Aventure Ambigue. Paris, Julliard.

HAMILTON, Carolyn (1998), Terrific Majesty. The Powers of Shaka Zulu and the Limits of Historical Invention. Cambridge, MA., Harvard University Press.

HAYNES, Jonathan (ed.) (2000), Nigerian Video Films. Columbus, Ohio University Center for International Studies.

HEGEL (1953), Reason in History. A General Introduction to the Philosophy of History (trad. Robert S. Hartman). New York, Liberal Arts Press.

HOUNTONDJI, Paulin (ed.) (1997), Endogeneous Knowledge: Research Trails. Dakar, CODESRIA.

IRELE, Abiola (1991), "African Letters: The Making of a Tradition". The Yale Journal of Criticism, vol. 5 , no 1 .

JEWSIEWICKI, Bogumil (1985), Marx, Afrique et Occident. Montréal, McGill University, Centre for Developing Areas.

KANT, I. (1965), Observations on the Feeling of the Beautiful and Sublime (trad. De John T. Goldthwait). Berkeley and Los Angeles, University of California Press.

_ (1978), Anthropology from a Pragmatic Point of View (trad. V. Lyle Dodwell). Chicago, University of Southern Illinois Press.

KI-ZERBO, Joseph (1972), Histoire de l'Afrique d'Hier à Demain. Paris, Hatier.

KOUROUMA, Ahmadou (2000), Allah n'Est pas Obligé. Paris, Seuil.

KRISTEVA, Julia (1982), Powers of Horror: An Essay on Abjection (trad. Leon S. Roudiez). New York, Columbia University Press.

KROG, Antjie (1998), Country of My Skull. Johannesburg, Random House.

KWAME, Anthony Appiah (1986/87), "Racism and Moral Pollution". Philosophical Forum, no 18.

_ (1992), In My Father's House. Africa in the Philosophy of Culture. London, Methuen.

LaCAPRA, Dominique (1998), “Trauma, Absence, Loss”. Critical Inquiry, vol. 11, n 2, pp. 441-464.

(1998), History and Memory after Auschwitz. Ithaca, Cornell University Press.

LAW, Robin (1985), "Human Sacrifice in Pre-Colonial West Africa”. African Affairs, no 34, pp. 53-87.

LONSDALE, John (1981), "The European Scramble and Conquest in African History”. In Cambridge History of Africa. Cambridge, Cambridge University Press.

LOVEJOY, Paul E. \& RICHARDSON, David (1999), "Trust, Pawnship, and Atlantic History: The Institutional Foundations of the Old Calabar Slave Trade". American Historical Review, abril, pp. 333-355.

LUGARD, Sir F.D. (1980), The Dual Mandate in British Tropical Africa. London, W. Blackwood \& Sons.

MacGAFFEY, Janet \& BAZENGUISSA-GANGA, Rémy (2000), Congo-Paris: Transnational Traders on the Margins of the Law. Oxford, James Currey.

MAFEJE, Archie (2000), "Africanity: A Combative Ontology". CODESRIA Bulletin, ${ }^{\circ}$ 1, pp. 66-71.

MAIR, L. (1936), Native Policies in Africa. London, Routledge \& Kegan Paul.

Estudos Afro-Asiáticos, Ano 23, no 1, 2001, pp. 206-209 
MALAQUAIS, Dominique (no prelo), “Anatomie d'une Arnaque. Feymen et Feymania au Cameroun".

MAMA, Amina; IMAM, Ayesha e SOW, Fatou (eds.) (1997), Engendering Social Sciences in Africa. Dakar, CODESRIA.

MAMDANI, Mahmood (1976), Politics and Class Formation in Uganda. New York, Monthly Review Press.

_ (1996), Citizen and Subject. Contemporary Africa and the Legacy of Late Colonialism. Princeton, NJ, Princeton University Press.

_ (ed.) (1997), Ugandan Studies in Labour. Dakar, CODESRIA.

_ \& WAMBA-DIA-WAMBA, Ernest (eds.) (1995), African Studies in Social Movements and Democracy, Dakar, CODESRIA.

MARAGNES, D. (s/d.), "L'Identité et le Désastre. Origine et Fondation". Portulan, no 98.

MARK, Peter (1999), “The Evolution of 'Portuguese' Identity: Luso-Africans on the Upper Guinea Coast from the Sixteenth to the Early Nineteenth Century". Journal of African History, no 40, pp. 173-191.

MBEMBE, Achille (2000), "At the Edge of the World: Boundaries, Territoriality, and Sovereignty in Africa". Public Culture, vol. 12, n 1.

_ (2001), On the Postcolony. Berkeley, University of California Press.

"Political Imagination in Times of War". (no prelo).

MEMEL-FOTÊ, Harris (1993), "La Fête de l'Homme Riche dans le Golfe de Guinée au Temps de l'Esclavage, XVIIe-XIXe Siècles”. Cahiers d'Études Africaines, no 131, pp. 363-379.

MERLEAU-PONTY, Maurice (1945), Phénoménologie de la Perception. Paris, Gallimard.

MILBANK, J. (1995), “Stories of Sacrifice: From Wellhausen to Girard”. Theory, Culture \& Society, vol. 12, no 4, pp. 15-46.

MILLER, Christopher (1998), Nationalists and Nomads. Essays on Francophone African Literature and Culture. Chicago, University of Chicago Press.

MILLER, Joseph (1988), Way of Death. Merchant Capitalism and the Angolan Slave Trade (1730-1830) Madison, WI, University of Wisconsin Press.

MILLS, C. W. (1998), Blackness Visible: Essays on Philosophy and Race. Ithaca, Cornell University Press.

MKANDAWIRE, Thandika \& OLUKOSHI, Adebayo (eds.) (1995), Between Liberalization and Oppression: The Politics of Structural Adjustment in Africa. Dakar, CODESRIA.

MKANDAWIRE, Thandika \& SOLUDO, Charles (1999), Our Continent, Our Future. Dakar: CODESRIA-IDRC.

MONENEMBO, Thierno (2000), L'Aîné des Orphelins. Paris, Seuil.

MONTESQUIEU (1979), De l'esprit des lois. Paris, Garnier-Flammarion.

MUDIMBE, V. Y. (1988), The Invention of Africa. Gnosis, Philosophy, and the Order of Knowledge Bloomington, Indiana University Press.

(1997), Tales of Faith: Religion as Political Performance in Central Africa (London, Atlantic Highlands.

Estudos Afro-Asiáticos, Ano 23, no 1, 2001, pp. 207-209 


\section{Achille Mbembe}

MUDIMBE, Valentin Y. (1991), Parables and Fables. Exegesis, Textuality, and Politics in Central Africa. Madison, WI, University of Wisconsin Press.

_ (1994), The Idea of Africa. Bloomington, Indiana University Press.

MWANGI, Wambui \& ZAIMAN, André (2000). "Race and Identity in Africa: A Concept Paper". CODESRIA Bulletin, no 1.

NEWELL, Stephanie (2000), Ghanaian Popular Fiction. "Thrilling Discoveries in Conjugal Life" \& Other Tales. Oxford, James Currey.

NGUGI wa Thiong'o (1986), Decolonising the Mind. London, James Currey.

NKRUMAH, Kwame (1961), I Speak of Freedom. London, Heinemann.

NUTTALL, Sarah (no prelo), "Subjectivities of Whiteness".

_ \& MICHAEL, Cheryl Ann (eds.) (2000), Senses of Culture. Cape Town, Oxford University Press.

NYERERE, Julius (1968), Ujamaa. Essays on Socialism. London, Oxford University Press.

OBENGA, Théophile (1973), L’Afrique dans l'Antiquité. Paris, Présence Africaine.

OUSHAKINE, Sergei A. (2000), "The Quantity of Style: Imaginary Consumption in the New Russia”. Theory, Culture \& Society, vol. 7, no 5.

PATTERSON, Orlando (1982), Slavery and Social Death. A Comparative Study. Cambridge, MA, Harvard University Press.

PÉCAUT, Daniel (2000), "Configurations of Space, Time, and Subjectivity in a Context of Terror: The Colombian Example". International Journal of Politics, Culture and Society, vol. 14, n ${ }^{\circ}$ 1, pp. 129-150.

PLUCHON, P. (1984), Nègres et Juifs au XVIIIe siècle. Paris, Taillandier.

RICOEUR, Paul (2000), La Mémoire, l'Histoire, l'Oubli. Paris, Seuil.

ROBINS, Steven (2000), "City Sites”. In S. Nuttall \& C. A. Michael (eds.) (2000), Senses of Culture. Cape Town, Oxford University Press, pp. 408-425.

RODNEY, Walter (1981), How Europe Underdeveloped Africa. Washington, D.C., Howard University Press.

SANSONE, Livio (1997), "The New Blacks from Bahia: Local and Global in Afro-Bahia”. Identities, no 3-4, pp. 457-493.

SCHOLEM, Gershom (2000), Aux Origines Religieuses du Judaïsme Lä̈que. De la Mystique aux Lumières. Paris, Calmann-Lévy.

SENGHOR, L. S. (1964), Liberté I: Négritude et Humanisme. Paris, Seuil. (1977), Liberté III: Négritude et Civilisation de l'Universel. Paris, Seuil.

SHAW, Rosalind (1997), "The Production of Witchcraft/Witchcraft as Production: Memory, Modernity, and Slave Trade in Sierra Leone”. American Ethnologist, n 24, pp. 856-876

SHIVJI, Issa (1976), Class Struggles in Tanzania. London, Heinemann.

_ (1988), Fight My Beloved Continent: New Democracy in Africa. Harare, SAPES Trust.

(1989), The Concept of Human Rights in Africa. Dakar, CODESRIA.

SIMONE, Abdoumaliq (no prelo), "The Worldling of African Cities".

SINGLETON, T. A. (1999), "The Slave Trade Remembered on the Former Gold and Slave Coasts". Slavery \& Abolition, no 20, pp. 150-169;

SMITH, Ian (1997), The Great Betrayal. London, Blake.

Estudos Afro-Asiáticos, Ano 23, no 1, 2001, pp. 208-209 
TAYLOR, Lucien (1998), "Créolité Bites. A Conversation with Patrick Chamoiseau, Raphael Confiant, and Jean Bernabé”. Transition, no 74, pp. 124-160.

TOCQUEVILlE, Alexis de (1988), De la Colonie en Algérie. Paris, Éditions Complexe. TUTU, Desmond (1984), Hope and Suffering. Grand Rapids, W.B. Erdmans.

VAN DER GEEST, Sjaak (2000), "Funerals for the Living: Conversations with Elderly People in Kwahu, Ghana”. African Studies Review, vol. 43, no 3, pp. 103-129.

VOLTAIRE (s/d), Oeuvres Complètes. Paris, Imprimerie de la Société Littéraire et Typographique.

WAMBA-DIA-WAMBA, Ernest (1998), "Mobutisme après Mobutu: Réflexions sur la Situation Actuelle en République Démocratique du Congo". Bulletin du CODESRIA, nos 3-4, pp. 27-34.

WILSON, H. S. (ed.) (1969), Origins of West African Nationalism. London, Macmillan-St Martin's Press.

WIREDU, Kwasi (1997), Cultural Universals and Particulars: An African Perspective. Gainesville, FL., University of Florida Press.

(2000), "How Not to Compare African Thought with Western Thought". In I. Karp \& D. A. Masolo (eds.), African Philosophy as Cultural Inquiry. Bloomington, Indiana University Press, pp. 187-214.

YAP, M. \& MANG, D. L. (1996), Colour, Confusion and Concessions. The History of the Chinese in South Africa. Hong Kong, Hong Kong University Press.

YERUSHALMI, Yosef H. (1982), Zakhor: Jewish History and Jewish Memory. Seattle, University of Washington Press.

ZELEZA, Paul Tiyambe (1993), A Modern Economic History of Africa. Volume I: The Nineteenth Century. Dakar, CODESRIA.

(1997), Manufacturing African Studies and Crises. Dakar, CODESRIA.

Estudos Afro-Asiáticos, Ano 23, no 1, 2001, pp. 209-209 